\title{
A CRISPR toolbox for generating intersectional genetic mouse models for functional, molecular, and anatomical circuit mapping
}

Savannah J. Lusk', Andrew McKinney ${ }^{1}$, Patrick J. Hunt², Paul G. Fahey' ${ }^{1}$, Jay Patel', Andersen Chang ${ }^{3}$, Jenny J. Sun ${ }^{1}$, Vena K. Martinez ${ }^{4}$, Ping Jun Zhu' ${ }^{1}$, Jeremy R. Egbert ${ }^{5}$, Genevera Allen ${ }^{6,7}$, Xiaolong Jiang ${ }^{1}$, Benjamin R. Arenkiel ${ }^{2,8}$, Andreas S. Tolias ${ }^{1}$, Mauro Costa-Mattioli ${ }^{1}$ and Russell S. Ray ${ }^{1,8^{*}}$

\begin{abstract}
Background: The functional understanding of genetic interaction networks and cellular mechanisms governing health and disease requires the dissection, and multifaceted study, of discrete cell subtypes in developing and adult animal models. Recombinase-driven expression of transgenic effector alleles represents a significant and powerful approach to delineate cell populations for functional, molecular, and anatomical studies. In addition to single recombinase systems, the expression of two recombinases in distinct, but partially overlapping, populations allows for more defined target expression. Although the application of this method is becoming increasingly popular, its experimental implementation has been broadly restricted to manipulations of a limited set of common alleles that are often commercially produced at great expense, with costs and technical challenges associated with production of intersectional mouse lines hindering customized approaches to many researchers. Here, we present a simplified CRISPR toolkit for rapid, inexpensive, and facile intersectional allele production.

Results: Briefly, we produced 7 intersectional mouse lines using a dual recombinase system, one mouse line with a single recombinase system, and three embryonic stem (ES) cell lines that are designed to study the way functional, molecular, and anatomical features relate to each other in building circuits that underlie physiology and behavior. As a proof-of-principle, we applied three of these lines to different neuronal populations for anatomical mapping and functional in vivo investigation of respiratory control. We also generated a mouse line with a single recombinase-responsive allele that controls the expression of the calcium sensor Twitch-2B. This mouse line was applied globally to study the effects of follicle-stimulating hormone (FSH) and luteinizing hormone (LH) on calcium release in the ovarian follicle.
\end{abstract}

\footnotetext{
* Correspondence: russell.ray@bcm.edu

'Department of Neuroscience, Baylor College of Medicine, Houston, TX, USA

${ }^{8}$ McNair Medical Institute, Houston, TX, USA

Full list of author information is available at the end of the article
}

(C) The Author(s). 2022 Open Access This article is licensed under a Creative Commons Attribution 4.0 International License, which permits use, sharing, adaptation, distribution and reproduction in any medium or format, as long as you give appropriate credit to the original author(s) and the source, provide a link to the Creative Commons licence, and indicate if changes were made. The images or other third party material in this article are included in the article's Creative Commons licence, unless indicated otherwise in a credit line to the material. If material is not included in the article's Creative Commons licence and your intended use is not permitted by statutory regulation or exceeds the permitted use, you will need to obtain permission directly from the copyright holder. To view a copy of this licence, visit http://creativecommons.org/licenses/by/4.0/ The Creative Commons Public Domain Dedication waiver (http://creativecommons.org/publicdomain/zero/1.0/) applies to the data made available in this article, unless otherwise stated in a credit line to the data. 
Conclusions: The lines presented here are representative examples of outcomes possible with the successful application of our genetic toolkit for the facile development of diverse, modifiable animal models. This toolkit will allow labs to create single or dual recombinase effector lines easily for any cell population or subpopulation of interest when paired with the appropriate Cre and FLP recombinase mouse lines or viral vectors. We have made our tools and derivative intersectional mouse and ES cell lines openly available for non-commercial use through publicly curated repositories for plasmid DNA, ES cells, and transgenic mouse lines.

Keywords: Intersectional genetics, Gene targeting, CRISPR/Cas9, Cre, Flp, Dre, DREADDs, Fluorescent reporter

\section{Background}

Targeted expression of effector molecules, like fluorescent markers, calcium reporters, optogenetic actuators, or exogenous ligand-responsive receptors (DREADDs) [1], are increasingly applied in a variety of fields for greater precision, quantitative expression level control, and reduced side effects compared to previous methods for labeling and manipulation. For example, the P1 bacteriophage cyclization recombinase gene (Cre)/ locus of crossover in P1 (LoxP) system is used to achieve permanent cell-type restriction by using a promoter or enhancer to express the site-specific recombinase Cre [2]. In such examples, Cre transgenes are paired with a constitutively active, but conditional, allele where expression of an effector molecule, such as enhanced green fluorescent protein (eGFP), is interrupted by a $\operatorname{LoxP}$ Stop-LoxP cassette that is recombined out by Cre, which enables expression in targeted, Cre-expressing cells. The use of various effector molecules in this paradigm enables fluorescent marking, neuronal perturbation, molecular affinity pull-downs, activity tracking, and other studies [1, 3-28].

In many fields, it is becoming increasingly clear that recombinase expression based on a single gene does not offer the resolution needed for a variety of developmental or targeting applications [29-31]. Indeed, application of intersectional genetics has led to new progress in various fields including neural circuits, cell-type lineage, and embryonic development [32-34]. Intersectional genetics adds needed resolution by employing a dual recombinase system using both Cre recombinase as well as a second recombinase, flippase (FLP), to activate a conditional effector allele only in cells where both recombinases have been expressed in the same cell (though not necessarily concurrently) [20, 35-42]. With new methodologies being developed to use Cre and FLP not only as traditional genetic markers, but also as activity and connectivity markers, unique combinatorial cell-type definitions become possible [43-47]. Thus, a resource consisting of multiple dual recombinase intersectional alleles that each express different effector molecules would add significant value and needed resolution to our ability to deconstruct neural circuits on multiple levels. This technology could also be applied to a multitude of other fields where intersectionally defined subpopulations of target cells exist and may play different roles in the measured outcomes.

Although mouse intersectional technology provides relatively benign access to otherwise inaccessible populations of cells, few laboratories have generated single transgenic or intersectional genetic mouse lines in house for several reasons. The complexity and size of the final targeting vectors puts them beyond present (cost-effective) commercial DNA synthesis capabilities, thus requiring some level of recombinant DNA cloning and precluding straightforward production of large, highfidelity ssDNA donors that can facilitate pronuclear clustered regularly interspaced short palindromic repeats (CRISPR)-mediated targeting [48]. While intersectional targeting vectors are available from the Addgene plasmid repository, they are finished vectors that require significant reverse engineering or modifications for use in a new context or approach. To our knowledge, there are no modular intersectional targeting vectors that are publicly available for facile and rapid production of new targeting alleles for the generation of intersectional mouse models. Furthermore, vector stability and other in vitro difficulties combined with the expense and time associated with target vector insertion and mouse line production limit the number of intersectional mouse lines available for public use. Thus, the production of intersectional genetic mouse lines has been largely limited to a small number of pioneering labs or resource-rich institutions such as the Howard Hughes Medical Institute and the Allen Institute for Brain Science [41, 49].

To address these pitfalls and make the production of intersectional genetic mouse models more widely feasible, we aimed to produce a freely available resource toolbox consisting of several intersectional and single recombinase-responsive Rosa26 targeting vectors for rapid, facile, and cost-effective generation of complex mouse lines using CRISPR/ CRISPR-associated protein 9 (Cas9)-mediated homologous recombination in mouse embryonic stem cells and early oocytes. In oocytes, genomic insertions/deletions (in/dels) and short targeted insertions are readily produced whereas large construct targeting in oocytes has shown more limited but growing success. Additionally, requisite equipment and 
facilities are difficult to access and out of reach for many investigators. ES cell approaches are well established and widely available, allowing for rapid screening and identification, and, if using morula aggregation, require much simpler methodologies and equipment for mouse generation.

Toward this, we produced 7 intersectional mouse lines using a dual recombinase system; one mouse line with a single recombinase system, and three additional ES cell lines to study how functional, molecular, and anatomical features relate to each other in building the circuits that underlie physiology and behavior. As a proof of principle, we applied three of these lines to different neuronal populations for anatomical mapping and functional in vivo characterization in respiratory control. Next, we globally applied the single recombinaseresponsive line, which controls the expression of the calcium sensor Twitch-2B. Twitch-2B was expressed globally in the generated mouse line to study the effects of follicle-stimulating hormone (FSH) and luteinizing hormone ( $\mathrm{LH})$ on calcium release in the ovarian follicle. The publication and availability of this technology will allow for the seamless production of a highly diverse group of mouse lines that can be used to generate animal models of human disease, label specific cell populations for developmental or connectivity studies, or modulate cellular activity in established disease model lines, among other possibilities. All reagents and vectors used or generated in this study are now openly available for not-for-profit research.

\section{Results}

\section{Vector design and optimization}

For each of the targeting vectors generated, the intersectional or Dre-responsive cassette was knocked into a well-established site in the Rosa26 locus (Fig. 1) [50, 51]. For positive ES cell clone selection, the targeting vector was simplified and improved in several ways compared to earlier approaches [52]. A simplified neomycin resistance cassette was integrated into the intersectional cassette before the second LoxP-flanked stop cassette to utilize the $C A G$ promoter and polyadenylation $(p A)$ sequences of the FLP recombinase target (FRT) flanked stop cassette, eliminating prior use of an additional 3phosphoglycerate kinase (PGK) promoter and Bovine Growth Hormone polyA (BGHpA) signal. To use CRISPR/ Cas9, we cloned an sgRNA that was close to the $5^{\prime} / 3^{\prime}$ homology junction into the px330 vector [53], which expresses both Cas 9 and the subcloned sgRNA ( $p \times 330_{-}$ Rosa26_sgRNA). A Woodchuck hepatitis virus (WHV) posttranscriptional regulatory element (WPRE) and BGHpA were added at the end of the expression cassette to enhance effector molecule expression and limit reliance on the disrupted Rosa locus for transcript termination [52]. The homology arms were significantly shortened to $1 \mathrm{~kb}$ to remove repetitive genomic sequences and stabilize the vector for prokaryotic propagation. Lastly, the terminal nonhomology Diphtheria Toxin A (DTA) chain negative selection cassette was removed, allowing for the complete targeting vector to be functionally tested via cell culture or in utero electroporation, which was not possible with the presence of the terminal DTA selection cassette without an additional subcloning step. Redesigned vectors and their Addgene ID numbers are outlined in Table 1 for public distribution.

\section{Embryonic stem cell electroporation}

We optimized traditional but widespread ES cell targeting by applying CRISPR/Cas9-mediated homologydirected repair (HDR) [54]. Our initial electroporation (EP) experiments using an earlier, more complex version of the Rosa26 intersectional targeting vector (containing the longer $4.2 \mathrm{~kb} \mathrm{3'}$ homology arm, DTA, and no CRISPR/Cas9) showed targeting rates ranging from 6 to $14 \%$ (over the course of four electroporations we saw targeting rates of $6 / 48,3 / 48,7 / 48$, and $3 / 48$ clones, mouse strains listed in Table 2). To determine the effect of CRISPR/Cas9 on targeting efficiency, we coelectroporated the $p \times 330 \_$Rosa26_sgRNA vector expressing Cas9 and a Rosa26-specific sgRNA with the optimized $R R 5$ targeting vector at four different molar ratios $(0: 1,0.5: 1,1: 1$, and $10: 1)$, proportionally decreasing the amount of donor vector to accommodate the increasing px330_Rosa26_sgRNA vector per EP $(18-20 \mu \mathrm{g}$ total DNA per EP for $1 \times 10^{7}$ ES cells) (Fig. 1 C). Under the 0:1 px330 vector:donor vector condition, we saw a $6 \%$ targeting rate similar to those seen in electroporations without Cas9 and with a much longer 3' homology arm and negative selection, suggesting that the shortening did not have a large impact on targeting efficiency under our EP conditions. Under the 0.5:1, 1:1, and 10:1 conditions, we observed 33\%, 27\%, and 58\% targeting, respectively, suggesting that higher ratios of the Cas 9 vector resulted in increased targeting efficiency (Fig. 1 D).

Since the 10:1 ratio had the highest targeting efficiency, despite having significantly less donor DNA, we used this ratio in subsequent EPs. Because the targeting efficiency was notably high, we next attempted a single electroporation with multiple vectors targeting the same locus, but containing equimolar amounts of five different cassettes, while keeping the overall px330_Rosa26_ $s g R N A$ vector to total donor vector ratio at 10:1. The five vectors consisted of: (1) a Cre/FLP-responsive mutant methionyl-tRNA synthetase (RR6) for selective labeling of newly synthesized proteins; (2) a Cre/FLP-responsive modified G-protein-coupled receptor (RR7); (3) a Cre/ FLP-responsive bicistronic reporter with H2B-TagBFP and sfGFP separated by a self-cleaving peptide derived 

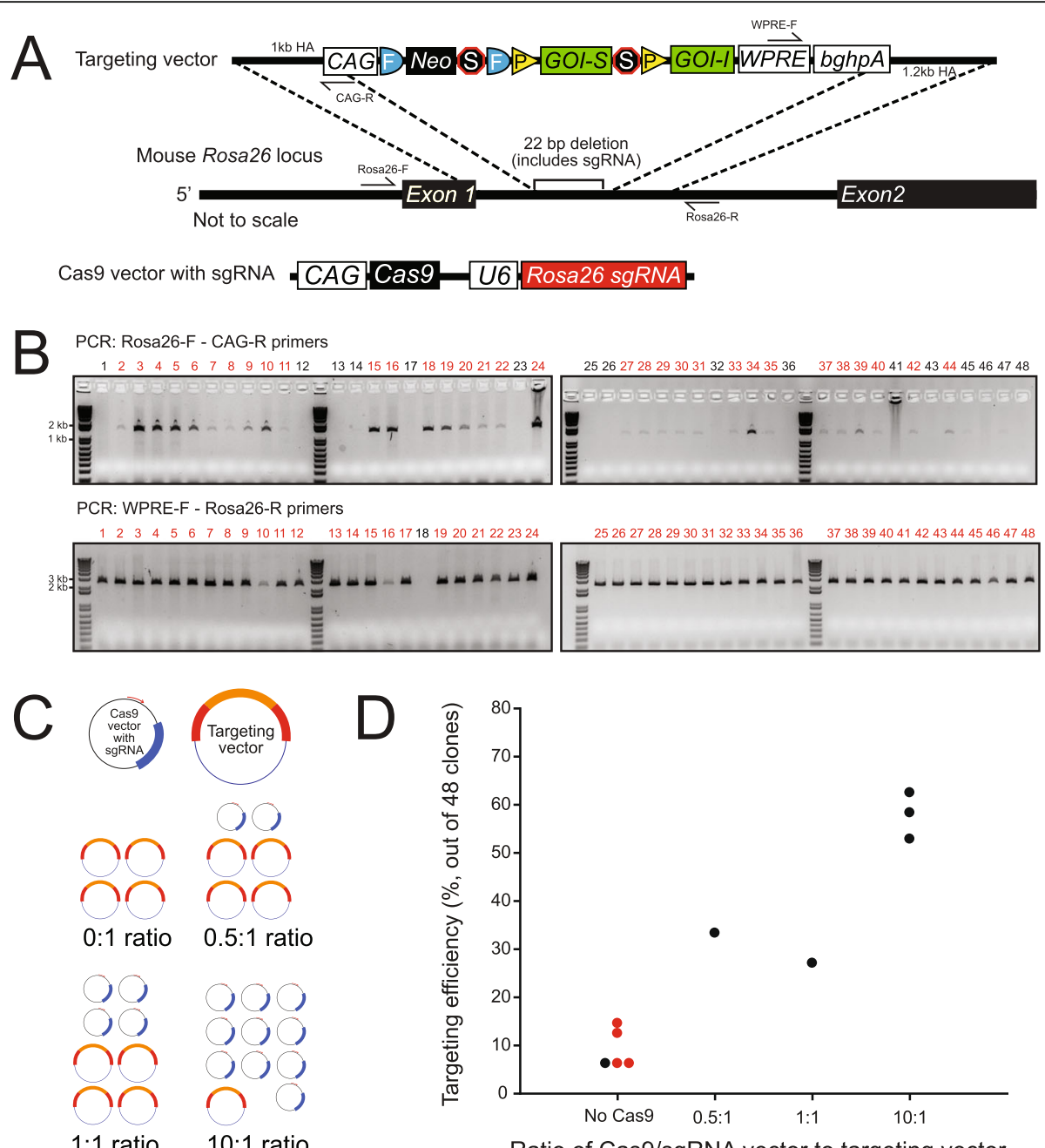

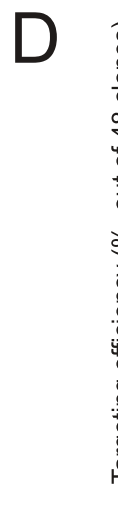

$1: 1$ ratio

$10: 1$ ratio

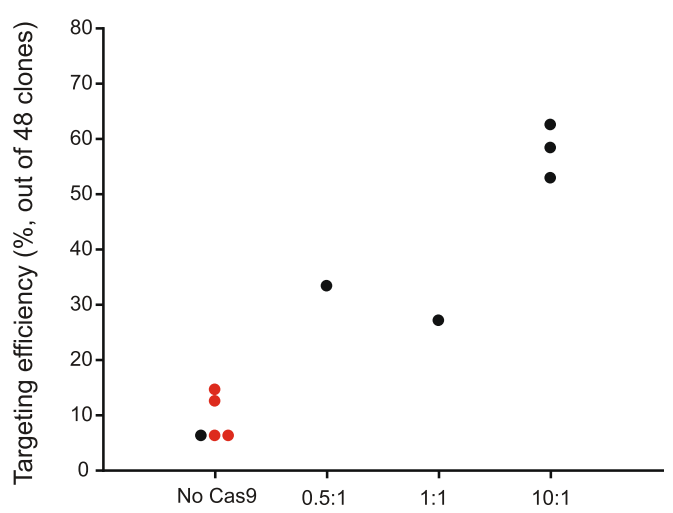

Ratio of Cas9/sgRNA vector to targeting vector

Fig. 1 Generation of intersectional Rosa26 mouse lines. A Targeting schematic showing the modular targeting vector containing a 1-kb 5' homology arm, CAG promoter, FRT-flanked neomycin and stop cassette, LoxP-flanked (optional) subtractive gene of interest (GOI-S) and stop cassette, intersectional gene of interest (GOI-I), WPRE, BGHPA element, and 1.2-kb 3' homology arm. The full intersectional cassette was knocked into the Rosa26 locus, with a 22-bp deletion of the CRISPR sgRNA. B PCR genotyping of neomycin selected ES cell clones. Targeting knock-in was determined using PCR primers that spanned from outside the Rosa26 homology arms to either the CAG promoter ( $5^{\prime}$ end) or WPRE ( $3^{\prime}$ end). Amplification of a band indicates targeting. Shown are results from a targeting event with over $60 \%$ targeting efficiency (RR7). C Four conditions with different Cas9:targeting vector ratios were used in our initial study: a 0:1 with no Cas9, 0.5:1, 1:1, and 10:1. D Targeting efficiency results from the different ratios. The 10:1 Cas9:targeting vector ratio showed a 5-10-fold increase over an electroporation with no Cas9. Shown in red are results from previous electroporations using the traditional Rosa26 targeting vector with more commonly used longer homology arms

from porcine teschovirus-1 targeting 2A (p2a) element, and tdTomato expressed in the subtractive population (cells that express FLP but not Cre) (RR9); (4) a Dreresponsive tricistronic reporter with histone $2 \mathrm{~B}$-tagged with blue fluorescent protein (H2B-TagBFP), superfolder GFP (sfGFP), and synaptophysin-tdTomato separated by p2a elements (RR11); and (5) a Dre-responsive bicistronic reporter with H2B-TagBFP and sfGFP separated by a p2a element (RR10). We saw a 52\% targeting efficiency and successful targeting of all five cassettes at varying efficiencies (Table 3). Due to the lower targeting efficiency of $R R 7$ (2\%), we attempted another 10:1 electroporation using the $R R 7$ donor vector alone and obtained a $63 \%$ targeting efficiency (genotyping results shown in Fig. 1). Thus, our results show that we are able to target and recover as many as five Rosa alleles in a single EP, significantly increasing efficiency and reducing costs toward intersectional mouse generation.

\section{Oocyte targeting}

Given the high efficiency of targeting, we also attempted to create a founder line (RR8) through direct oocyte 
Table 1 Publicly available modular targeting vectors for rapid generation of recombinase-responsive ES cells and mouse lines

\begin{tabular}{|c|c|c|}
\hline Vector & Function & $\begin{array}{l}\text { Addgene } \\
\text { ID Number }\end{array}$ \\
\hline CAG Cas9 U6 Rosa26 sgRNA & $\begin{array}{l}\text { Cas9 (px330) vector } \\
\text { with sgRNA }\end{array}$ & 97007 \\
\hline 5' homology arm $\quad$ CAG $\mathrm{NeO} S \mathrm{~S}$ & $\begin{array}{l}\text { FLP and Cre responsive } \\
\text { cloning vector }\end{array}$ & 97012 \\
\hline 5' homology arm $\quad C A G, F=S$ & $\begin{array}{l}\text { FLP and Cre responsive } \\
\text { cloning vector (no neo) }\end{array}$ & 99142 \\
\hline 5' homology arm $\quad$ CAG $\mathrm{P}$ Neo & $\begin{array}{l}\text { Cre responsive } \\
\text { cloning vector }\end{array}$ & 97009 \\
\hline 5' homology arm CAG & $\begin{array}{l}\text { FLP responsive } \\
\text { cloning vector }\end{array}$ & 97010 \\
\hline 5' homology arm $C A G=$ & $\begin{array}{l}\text { Dre responsive } \\
\text { cloning vector }\end{array}$ & 97011 \\
\hline 5' homology arm & $\begin{array}{l}\text { Empty Rosa26 } \\
\text { targeting vector }\end{array}$ & 97008 \\
\hline
\end{tabular}

${ }^{*} \mathrm{CS}$ : Cloning site

injection of the optimized Rosa26 targeting vector with a Cre-responsive calcium indicator, Twitch [55] (total cassette size without homology arms, $6.5 \mathrm{~kb}$ ), using pronuclear injection of Cas 9 protein $(30 \mathrm{ng} / \mu \mathrm{l})$, sgRNA (20 $\mathrm{ng} / \mu \mathrm{l})$, and double-stranded DNA plasmid $(2 \mathrm{ng} / \mu \mathrm{l})$. A total of 1266 embryos were injected yielding 129 mice, of which 7 genotyped positive for the calcium indicator but only one targeted successfully $(<1 \%$ targeting efficiency of mice born), suggesting that direct oocyte injection is inefficient with this system under the specified parameters.

\section{Off-target analysis}

Genomic sequences that are similar to the sgRNA used for targeted double-stranded breaks may cause unintended gene mutations or editing at off-target sites. To account for this possibility, we predicted the off-target sites for each sgRNA using the crispr.mit.edu tool and selected the top 5 sites for follow-up. We PCR amplified and sequenced these loci from three correctly targeted ES cell clones and did not detect any genetic changes (Fig. 2). While we cannot rule out off-target effects in other loci, these data suggest that off-target effects are not prevalent in this setting.

\section{Mouse line derivation}

The goal of our efforts was to produce freely available genetic tools that delineate and access distinct populations for multifaceted circuit mapping or functional characterization studies. With this toolkit in hand, we collectively produced 11 intersectional or Dre-responsive alleles available as either mouse lines (8) or ES cells (3) (Table 2). To perturb neuron function, we produced three lines that express metabotropic DREADD receptors, modified human M4 muscarinic receptor (hM4D) (RR1), modified human M3 muscarinic receptor (hM3D) $(R R 2)$, and RASSL (Rs)-EGFP (RR7), and a fourth line expressing the ionotropic pharmacologically selective actuator module (PSAM) receptor (RR4) [24, 56, 57]. Two lines enable molecular characterization: one expresses the EGFP-L10A fusion protein for ribosomal affinity purification and capture of translating mRNAs (RR3) [58], while the second line expresses methionyl-tRNA synthetase (Met-RS) that incorporates an artificial amino acid into nascent peptides (RR6) [13]. One line enables ratiometric calcium imaging via expression of Twitch2B (RR8). Our neuro-anatomical mapping lines described below also incorporate a tagged histone (H2B), offering the possibility of chromatin affinity isolations. We 
Table 2 Rosa26 knock-in alleles generated with or without CRISPR/Cas9 methods. Shown are targeted Rosa26 alleles, function, length of cassette, current status, and expected MGI name (to be determined) in grey rows

\begin{tabular}{|c|c|c|c|c|c|}
\hline $\begin{array}{l}\text { Short } \\
\text { Name }\end{array}$ & $\begin{array}{l}\text { MMRRC } \\
\text { ID }\end{array}$ & $\begin{array}{c}\text { Subtractive } \\
\text { gene }\end{array}$ & $\begin{array}{l}\text { Intersectional } \\
\text { gene }\end{array}$ & Function & Line status \\
\hline$R R 1^{*}$ & 43516 & mCherry & $h M 4 D$ & $\begin{array}{l}\text { Metabotropic neuron } \\
\text { perturbation }\end{array}$ & $\begin{array}{l}\text { Established and } \\
\text { functional }\end{array}$ \\
\hline \multicolumn{6}{|c|}{ Gt(ROSA)26Sor ${ }^{t m \#(C A G-m C h e r r y,-h M 4 D) R r a y}$} \\
\hline$R R 2^{*}$ & 43515 & mCherry & $h M 3 D$ & $\begin{array}{l}\text { Metabotropic neuron } \\
\text { stimulation }\end{array}$ & $\begin{array}{l}\text { Established and } \\
\text { functional }\end{array}$ \\
\hline \multicolumn{6}{|c|}{ Gt(ROSA)26Sor ${ }^{t m \#(C A G-m C h e r r y,-h M 3 D) R r a y ~}$} \\
\hline$R R 3^{*}$ & 43518 & mCherry & $E G F P-L 10 A$ & Translating mRNA pulldown & Established \\
\hline \multicolumn{6}{|c|}{ Gt(ROSA)26Sor $r^{t m \#(C A G-m C h e r r y,-E G F P-L 10 A) R r a y ~}$} \\
\hline$R R 4^{*}$ & 43519 & mCherry & PSAM & Ionotropic neuron perturbation & Established \\
\hline \multicolumn{6}{|c|}{ Gt(ROSA)26Sor ${ }^{t m \#(C A G-m C h e r r y,-P S A M) R r a y ~}$} \\
\hline$R R 5$ & 43513 & None & $\begin{array}{l}\text { H2B-TagBFP; sfGFP; } \\
\text { synaptophysin-tdTomato }\end{array}$ & $\begin{array}{l}\text { Intersectional fluorescent } \\
\text { marking }\end{array}$ & $\begin{array}{l}\text { Established and } \\
\text { functional }\end{array}$ \\
\hline \multicolumn{6}{|c|}{ Gt(ROSA)26Sor ${ }^{t m \#(C A G-H 2 B-T a g B F P-s f G F P-s y n a p t o p h y s i n-t d T o m a t o) R r a y ~}$} \\
\hline$R R 6$ & 43517 & mCherry & Met-RS & Synthesized protein pulldown & Established \\
\hline \multicolumn{6}{|c|}{ Gt(ROSA)26Sor ${ }^{t m \#(C A G-m C h e r r y,-M e t R S) R r a y ~}$} \\
\hline$R R 7$ & 43514 & mCherry & Rs-EGFP & Metabotropic Gs excitation & Established \\
\hline \multicolumn{6}{|c|}{ Gt(ROSA)26Sortm\#(CAG-mCherry,-Rs-eGFP)Rray } \\
\hline$R R 8$ & $T B D$ & None & Twitch2B & Ratiometric calcium imaging & $\begin{array}{l}\text { Established and } \\
\text { functional }\end{array}$ \\
\hline \multicolumn{6}{|c|}{ Gt(ROSA)26Sor ${ }^{t m \#(C A G-T w i t c h 2 B) R r a y ~}$} \\
\hline$R R 9$ & & tdTomato & $\begin{array}{l}\text { H2B-TagBFP; } \\
\text { sfGFP }\end{array}$ & $\begin{array}{l}\text { Subtractive and intersectional } \\
\text { fluorescent marking }\end{array}$ & Targeted ES cells \\
\hline \multicolumn{6}{|c|}{ Gt(ROSA)26Sor ${ }^{\text {tm\#(CAG-tdTomato,-H2B-TagBFP-sfGFP)Rray }}$} \\
\hline$R R 10$ & & None & $\begin{array}{l}\text { H2B-TagBFP; } \\
\text { sfGFP }\end{array}$ & $\begin{array}{l}\text { Dre-responsive fluorescent } \\
\text { marking }\end{array}$ & Targeted ES cells \\
\hline \multicolumn{6}{|c|}{ Gt(ROSA)26Sor ${ }^{t m \#(C A G-H 2 B-T a g B F P-s f G F P) R r a y}$} \\
\hline$R R 11$ & & None & $\begin{array}{l}\text { H2B-TagBFP; sfGFP; } \\
\text { synaptophysin-tdTomato }\end{array}$ & $\begin{array}{l}\text { Dre-responsive fluorescent } \\
\text { marking }\end{array}$ & Targeted ES cells \\
\hline
\end{tabular}

Grey rows highlight Mouse Genome Informatics names; (tm\#) are currently being determined

*Made using an earlier Rosa26 targeting vector without CRISPR/Cas9

created four alleles of differing Cre, FLP, and Dre recombinase-responsive configurations that fluorescently mark distinct cellular compartments for unambiguous cell counts, morphological characterizations, and projection mapping (RR5, RR9, RR10, RR11). The derivation of lines $R R 5, R R 6$, and $R R 7$ demonstrated that ES pluripotency was maintained and that germline transmission was not diminished in our Cas9-mediated single and multiplexed electroporations after correctly targeted clones were selected and injected into blastocysts for chimera generation.

\section{Select mouse line characterization}

Upon dual recombinase expression, the RR5 tricistronic multi-color reporter allele expresses three spectrally separated and modified fluorescent proteins to highlight the nucleus in blue, fill the neuron in green, and emphasize presynaptic contacts in red. At the site of dual recombinase expression, targeted cells are brightly labeled with TagBFP, sfGFP, and tdTomato where TagBFP fluorescence is constrained to the nucleus by an H2B fusion, sfGFP is unmodified so that fluorescence is seen throughout the cell body, and tdTomato is fused to 
Table 3 Targeting efficiencies for a multiplexed five cassette ES cell electroporation for the Rosa26 locus

\begin{tabular}{|c|c|c|c|c|}
\hline \multicolumn{5}{|l|}{ RR1-4 ES cell targeting vectors without Cas9 } \\
\hline Knock-in Cassette & \multicolumn{2}{|c|}{ Short name } & Length & Efficiency \\
\hline 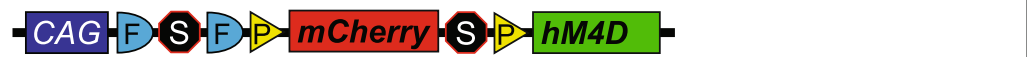 & \multicolumn{2}{|c|}{$R R 1$} & 9312 bps & $6 / 48(13 \%)$ \\
\hline 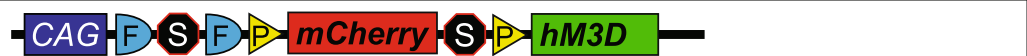 & \multicolumn{2}{|c|}{$R R 2$} & 9328 bps & $3 / 48(6 \%)$ \\
\hline 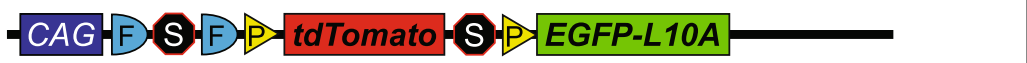 & \multicolumn{2}{|c|}{$R R 3$} & 9006 bps & $7 / 48(14 \%)$ \\
\hline -CAGSFS-FP tdTomato-S $P$ PSAM - & \multicolumn{2}{|c|}{$R R 4$} & 8790 bps & $3 / 48(6 \%)$ \\
\hline \multicolumn{5}{|l|}{ RR5 -ES cell Cas9 co-electroporation knock-in efficiencies. } \\
\hline \multicolumn{2}{|l|}{ RR5 Knock-in Cassette (12641 bp) } & \multicolumn{2}{|c|}{ Cas9:Vector } & Efficiency \\
\hline \multicolumn{2}{|l|}{ 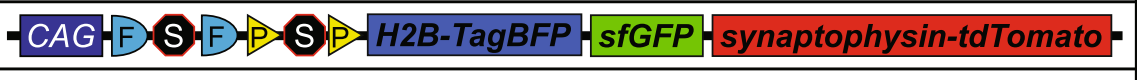 } & \multicolumn{2}{|r|}{$0: 1$} & $3 / 48(6 \%)$ \\
\hline \multicolumn{2}{|l|}{-CAG $\mathrm{F}$ S $\mathrm{F}-\mathrm{P}, \mathrm{S} \mathrm{P}-\mathrm{H} 2 \mathrm{~B}-\mathrm{TagBFP}$ sfGFP synaptophysin-tdTomato } & \multicolumn{2}{|r|}{$0.5: 1$} & $16 / 48(33 \%)$ \\
\hline \multicolumn{2}{|l|}{-CAG $\mathrm{F} S \mathrm{~S}-\mathrm{F}-\mathrm{P}, \mathrm{S} P \mathrm{P}-\mathrm{H} 2 \mathrm{~B}-\mathrm{TagBFP}$ sfGFP synaptophysin-tdTomato- } & \multicolumn{2}{|r|}{$1: 1$} & $13 / 48(27 \%)$ \\
\hline \multicolumn{2}{|l|}{-CAG $\mathrm{F}$ S $\mathrm{F}-\mathrm{P}$ S $\mathrm{P}-\mathrm{H2B}-\mathrm{TagBFP}$ sfGFP synaptophysin-tdTomato } & \multicolumn{2}{|r|}{ 10:1 } & $28 / 48(58 \%)$ \\
\hline \multicolumn{5}{|c|}{ Multiplex ES cell cas9 knock-in efficiencies (Cas9 : Vector $=10 .: 1$ ) } \\
\hline Knock-in Cassette & \multicolumn{2}{|c|}{ Short name } & Length & Efficiency \\
\hline F $P$ - m Cherry $S-P=$ Met-RS & \multicolumn{2}{|c|}{$R R 6$} & 11037 bps & $6 / 48(13 \%)$ \\
\hline FP $P$ Cherry S-P $R$ Rs-EGFP & \multicolumn{2}{|c|}{$R R 7$} & 9534 bps & $1 / 48(2 \%)$ \\
\hline 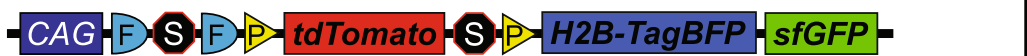 & \multicolumn{2}{|c|}{$R R 9$} & 9597 bps & $6 / 48(13 \%)$ \\
\hline CAG $R-S-R$ H2B-TagBFP sfGFP synaptophysin-tdTomato- & \multicolumn{2}{|c|}{$R R 11$} & 9202 bps & $5 / 48(10 \%)$ \\
\hline$-C A G-R-R-H 2 B-T a g B F P=$ sfGFP- & \multicolumn{2}{|c|}{ RR10 } & 6732 bps & $9 / 48(19 \%)$ \\
\hline \multicolumn{4}{|c|}{ Multiplex vector electroporation total } & $25 / 48(52 \%)$ \\
\hline \multicolumn{5}{|l|}{ Oocyte cas9 knock-in efficiencies } \\
\hline$-C A G \mathbb{P} \times \mathrm{S}-$ Twitch 2B- & \multicolumn{2}{|c|}{$R R 8$} & $6508 \mathrm{bps}$ & $1 / 1266(<1 \%)$ \\
\hline
\end{tabular}

synaptophysin [59] so that fluorescence is excluded from nuclear areas and primarily seen in projection areas. Individual nuclei can be resolved using blue fluorescence and co-localization with sfGFP-labeled somata.

We used $R R 5$ to evaluate the functional activity and specificity in vivo of our CRISPR/Cas9 approach to generating mouse lines in three distinct contexts; (1) germline recombinase expression, (2) viral recombinase expression, and (3) combinatorial retrograde viral and germline recombinase expression to target single gene defined neurons by a specific projection field. First, to demonstrate genetically restricted, germline expression of recombinases in the intersectional $R R 5$ line, we bred the $R R 5$ line to a

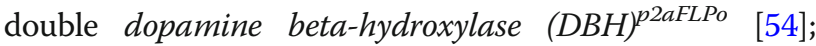
Bactin-Cre recombinase driver to express the tricistronic fluorescent cassette in $\mathrm{DBH}$-positive noradrenergic (NA) neurons in the brainstem (Fig. $3 \mathrm{~A}-\mathrm{H}$, Additional File 1: Fig. S1 A-B). In both the locus coeruleus (LC) (Fig. 3 AD) and the A5 nucleus (Fig. $3 \mathrm{E}-\mathrm{H}$ ) as well as all other noradrenergic nuclei (not shown), we could cleanly resolve blue nuclei, green cells, and red puncta without the need for antibody enhancement. Additionally, we bred an intersection of double vesicular GABA transporter (Vgat)-Cre; vesicular glutamate transporter 2 (Vglut2)FLPo recombinase expression to the RR5 line and found the entopeduncular nucleus labeled green with local projections labeled red and distal projections in the lateral habenula labeled red (4'-6-diamidino-2-phenylindole (DAPI) was applied to help delineate the target field, obscuring the genetic TagBFP signal )[60, 61] (Fig. 3I-P). 


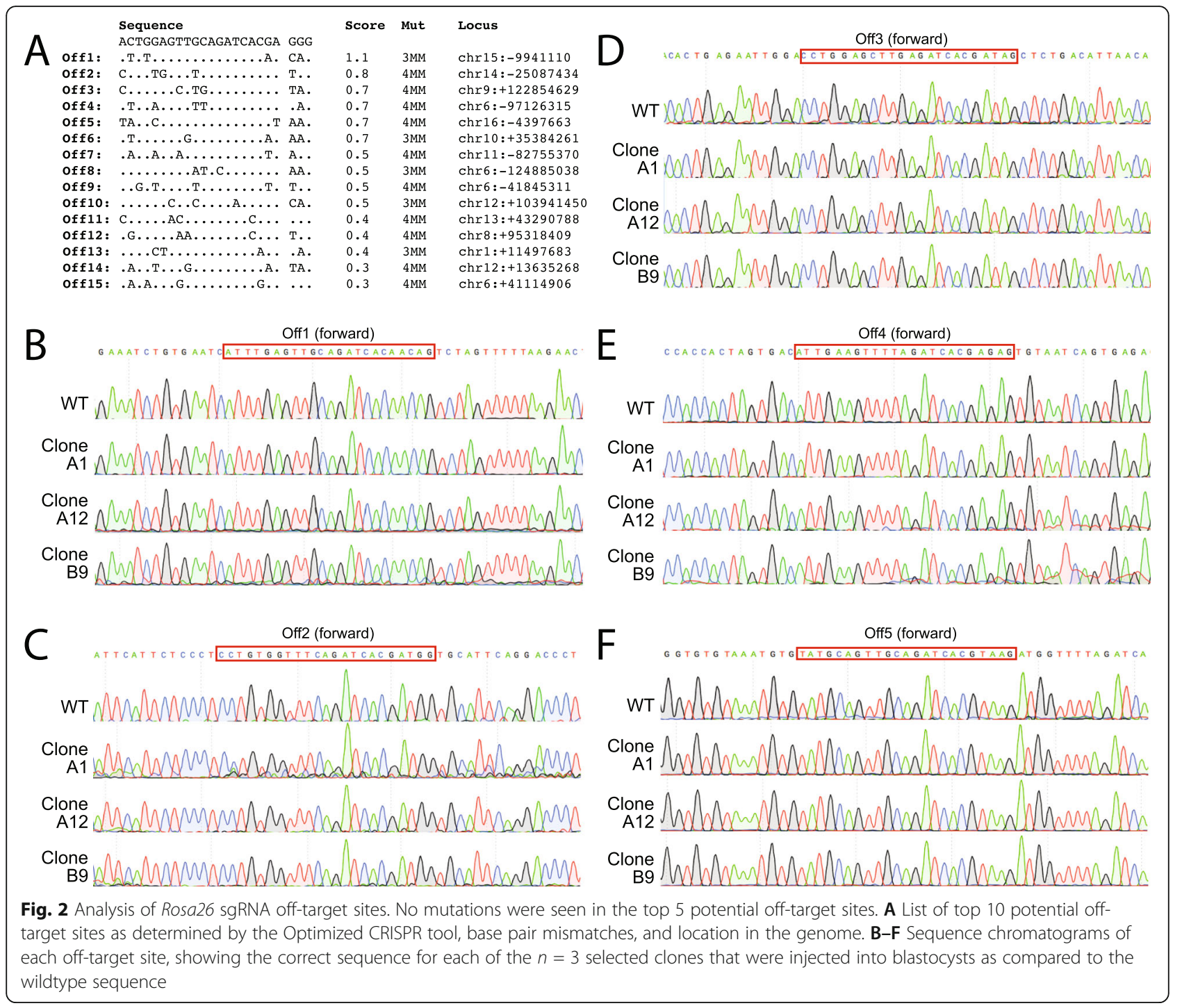

Second, we verified viral expression of Cre and FLP recombinase where adult $R R 5$ mice were stereotaxically injected with equal titer amounts of adeno-associated viruses (AAVs) expressing Cre and FLP (Fig. 4A, Additional File 1: Fig. S1 C) into the dentate gyrus (Fig. 4B-I), amygdala (Fig. 4J-Q), and olfactory bulb (Fig. 4R-U). Clear expression of all three fluorescent proteins were resolved at the site of injection to the appropriate cellular locations. Third, defining properties of the subpopulations can be extended to include any combination of gene expression or anatomical location and projection target when injection of retrograde viral vectors is applied. To utilize this option, we genetically marked a neuronal subtype defined by the partial overlap of a genetic selector and projection target by injecting canine adenovirus 2 (CAV2)-Cre virus $[62,63]$ into the basolateral amygdala of $D B H^{p 2 a F L P o}$; $R R 5$ mice that express only FLP in all noradrenergic neurons. CAV2-Cre virus efficiently transduces axon terminals, thus genetically marking presynaptic neurons. In this context, only noradrenergic neurons expressing $\mathrm{DBH}$ that project to the amygdala express both Cre and FLP and the resulting tricistronic fluorescent cassette (Fig. 5A). We only observed recombination in the brainstem noradrenergic nuclei and in the locus coeruleus, primarily on the ipsilateral side (Fig. 5B-E) with some sparse marking on the contralateral side (Fig. 5F-I), in agreement with a prior study [64]. Overlapping red and green puncta (with no blue) could be seen in the injected amygdala, suggesting that the marked neurons project to the amygdala, as expected given the nature of the CAV2-Cre virus (Fig. 5J-M). We also observed collateral projections to several additional areas in the mid and forebrain, including the dorsal raphé (Fig. 5N-Q), reticulotegmental pontine 


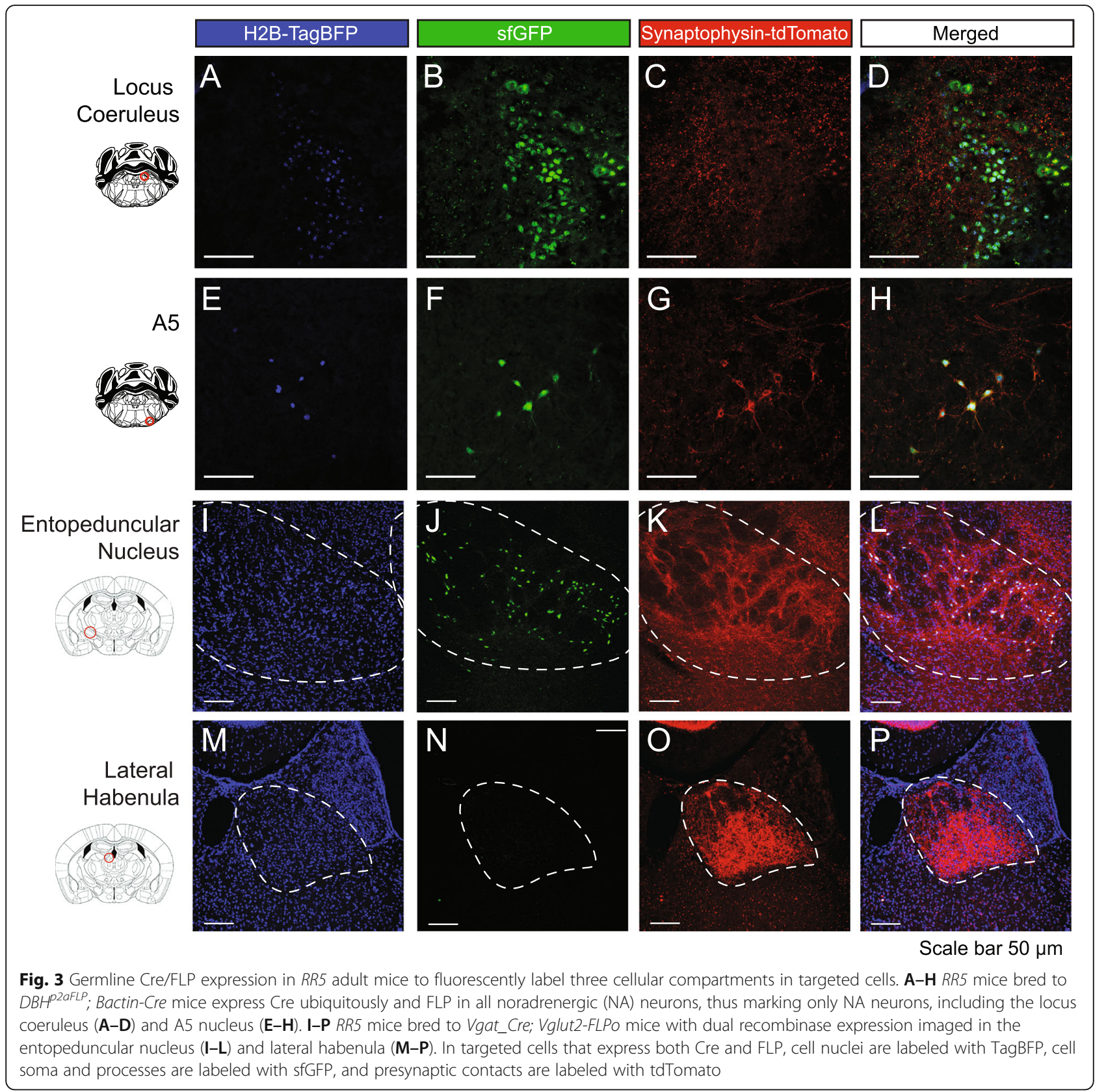

nuclei (Fig. 5R-U), dentate gyrus (Fig. 5V-Y), and olfactory bulb (Fig. $5 \mathrm{Z}-\mathrm{CC}$ ). This restriction by retrograde selection was also achieved in other regions of the brain with a second viral vector. Vglut2_Cre; RR5 mice were injected with retro-AAVEf1a-FLPo into the lateral hypothalamus (Fig. 6A) where tricistronic expression was clearly visualized in the cingulate gyrus (Fig. 6B-E), piriform cortex (Fig. 6F-I), and medial habenula (Fig. 6J-M), indicating these regions as presynaptic inputs to the lateral hypothalamus. Together, these results are in agreeance with previous connectivity studies [64].
Before in vivo characterization of the DREADD systems coded by $R R 1$ and $R R 2$, we first examined the ability of the $R R 1$ and $R R 2$ lines to modulate dopamine beta-hydroxylase (DBH)-defined noradrenergic neuron activity at the cellular level. We conducted whole-cell recordings from postnatal day (P)30-P60 locus coeruleus neurons expressing one of 3 DREADD receptors: hM3D (RR2), hM4D (RR1), or Di (previously published). Each cassette exists with FRT and LoxP bound stop cassettes, so each line was initially bred with Bactin_FLPe to remove the FLP-dependent stop cassette [65]. The RC::FrePe was also bred with Bactin_FLPe to remove the FLP-dependent stop cassette and then bred to 


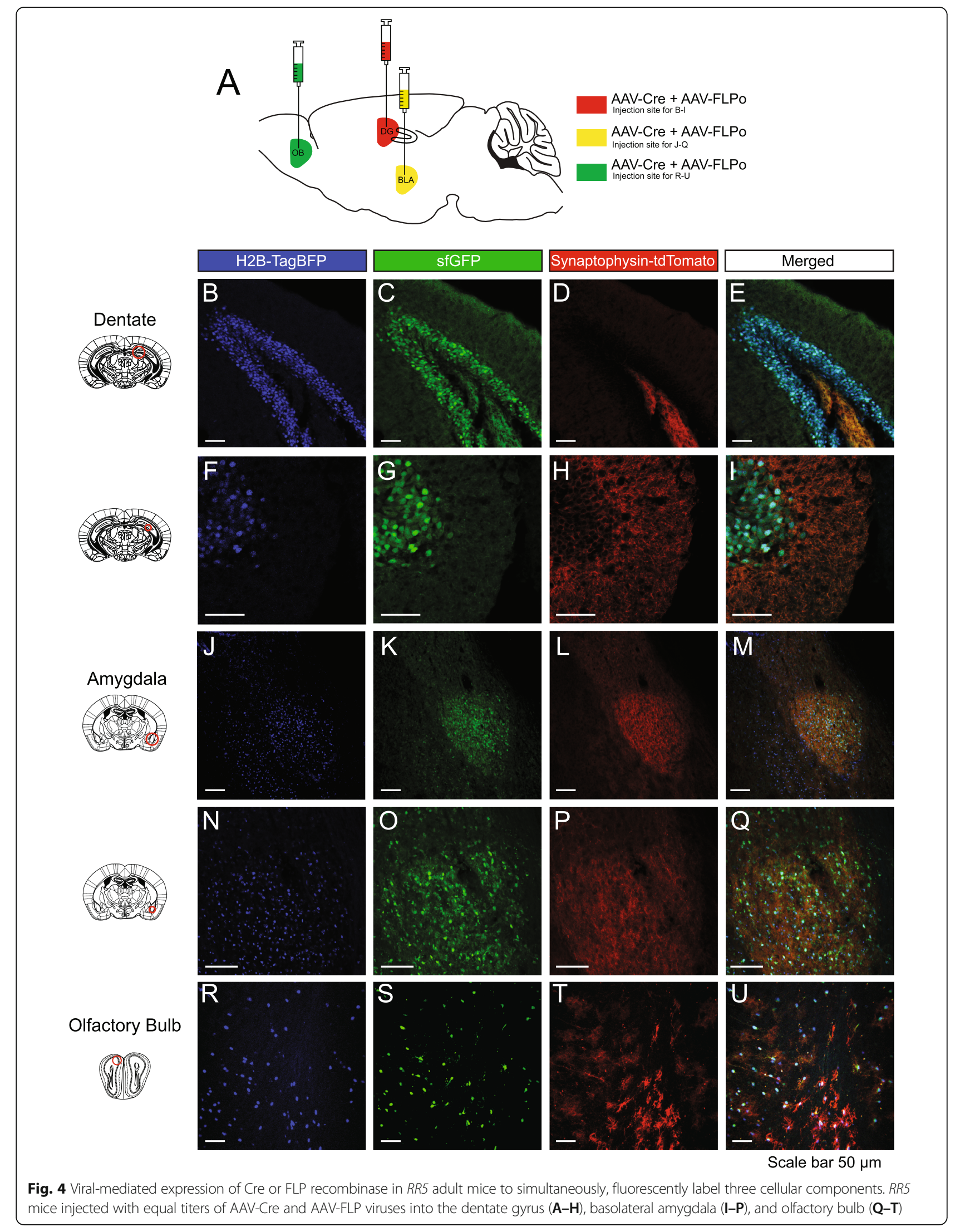



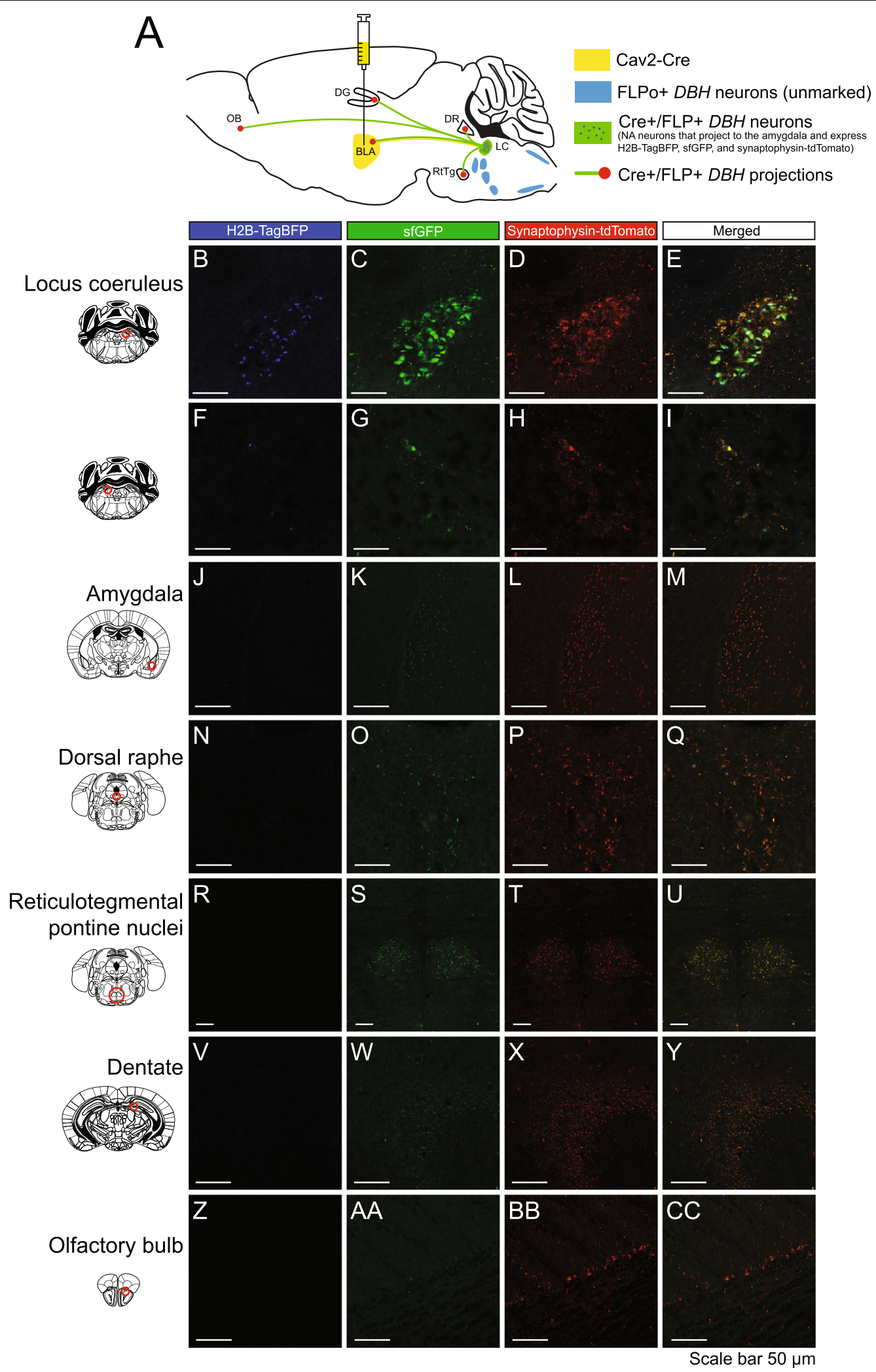

Fig. 5 (See legend on next page.) 
(See figure on previous page.)

Fig. 5 Retrograde viral Cre and germline FLP mediated expression of dual recombinases for tricistronic FP expression on RR5 background. A RR5; $D B H^{\text {P2aFLPo }}$ mice were injected with CAV2-Cre virus into the basolateral amygdala. All DBH noradrenergic neurons express FLP, but only those noradrenergic neurons projecting to the injected amygdala will also express Cre. Marked double Cre/FLP-positive cells will express H2B-TagBFP highlighting the nucleus in blue, sfGFP filling the cell including the axon, and synaptophysin-tdTomato labeling presynaptic contacts. BLA: Basolateral amygdala. DG: Dentate gyrus. DR: Dorsal raphé. LC: Locus coeruleus. OB: Olfactory bulb. RtTg: Reticulotegmental pontine nucleus. DBHpositive neurons that project to the amygdala arise primarily from the ipsilateral locus coeruleus (B-E) with some sparse labeling in the contralateral locus coeruleus (F-I). Red puncta overlapping with green but lacking blue marked nuclei (indicative of projections from the marked population) can be seen in a variety of mid- and forebrain areas, including the injected amygdala (J-M), the raphé nucleus ( $\mathbf{N}-\mathbf{Q})$, reticulotegmental pontine nuclei $(\mathbf{R}-\mathbf{U})$, dentate gyrus $(\mathbf{V}-\mathbf{Y})$, and olfactory bulb (Z-CC)

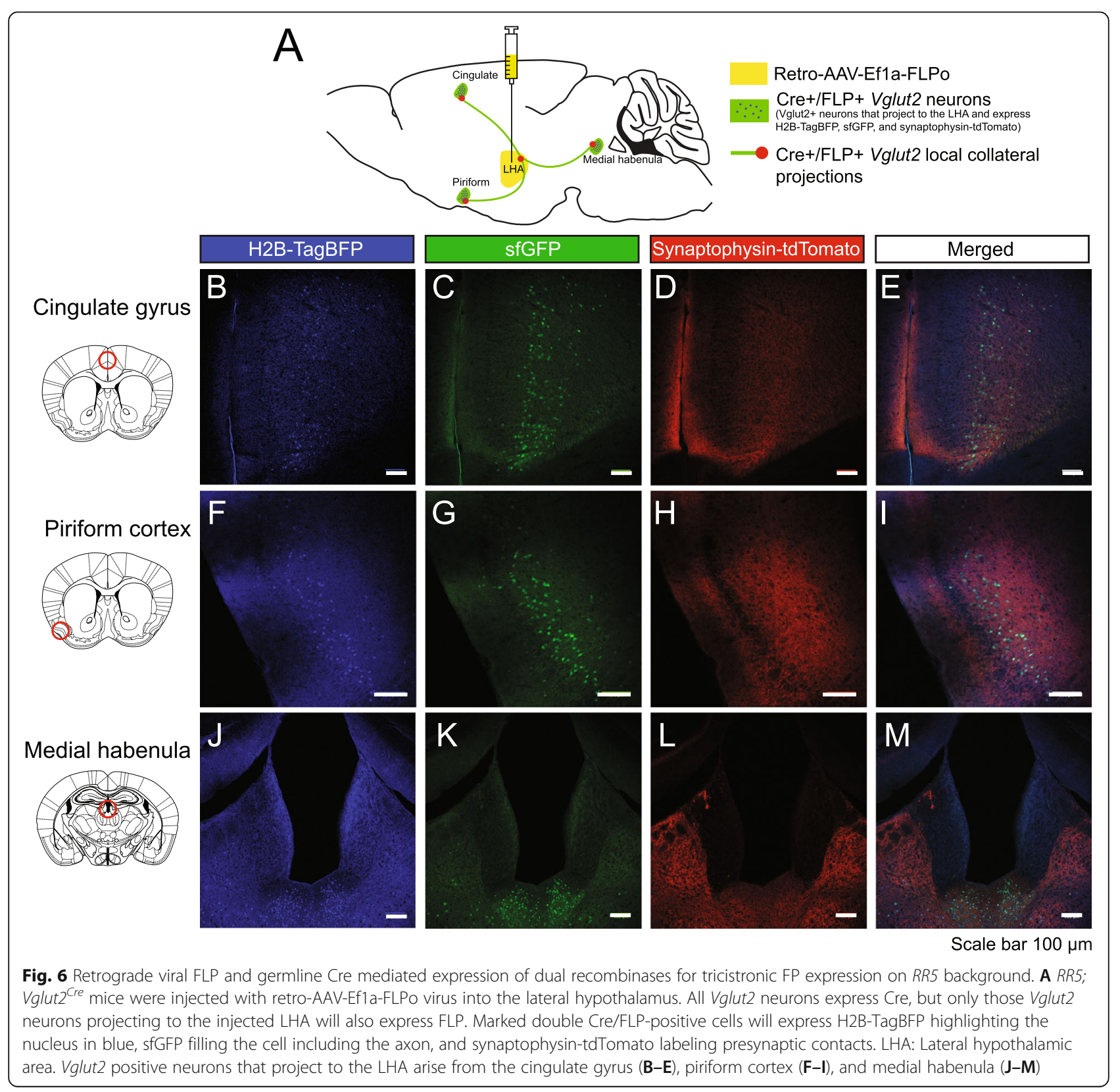


the cre-only dependent DREADD lines [66]. This compound allowed for fluorescent labeling of neurons where Cre recombinase, and thus DREADD receptors, are present. These compounds resulted in mice wherein GFP and a DREADD were expressed in TgDBH-Cre-defined cells for acute brain slice visualization (See Additional File 2: Fig. S2 for further genetic details). $R C:: P D i$ [52] was included as it represents a similarly constructed hM4D intersectional allele, but lacks the modifications and optimizations made in our targeting system (Fig. 1A). For example, $R C:: P D i$ contains an additional PGK Promoter and $p A$ signal sequence flanking neomycin in the first stop cassette and lacks the WPRE element and $p A$ found in RR1 and RR2. We hypothesized that the addition of a WPRE would enhance DREADD effectiveness. After bath application of $10 \mu \mathrm{M}$ clozapine-N-oxide (CNO), for RR2P (hM3D); $R C$ ::epe we observed a depolarization of membrane potentials of LC neurons (pre-CNO: $-62.26 \pm 1.53$, post-CNO: $-55.09 \pm 2.16 \mathrm{mV}$, paired $t$-test: $p=0.0034, n=19$ neurons across 3 mice). After bath application of $10 \mu \mathrm{M} \mathrm{CNO}$, for RR1P (hM4D); RC::epe, we observed a hyperpolarization of membrane potentials of LC neurons (pre-CNO: $-56.98 \pm$ $3.50 \mathrm{mV}$, post-CNO: $-65.3137 \pm 3.60 \mathrm{mV}$, paired $t$-test: $p$ $=0.046, n=10$ neurons across 3 mice). After bath application of $10 \mu \mathrm{M} C \mathrm{CNO}$, for $R C:: P D i(D i)$; $R C:: e p e$, we observed a hyperpolarization of membrane potentials (preCNO: $-53.71 \pm 2.93 \mathrm{mV}$, post-CNO: $-56.72 \pm 3.42 \mathrm{mV}$, paired $t$-test: $p=0.027, n=10$ neurons across 3 mice) (Fig. 7A-C). These data confirmed functional expression of each DREADD system. All raw data from these experiments are available on Zenodo (10.5281/zenodo.5794197).

We next performed whole-body plethysmography to assess changes in respiratory function caused by $\mathrm{CNO}$ DREADD-mediated perturbation of targeted neurons in vivo. Significant changes in any of the calculated respiratory variables demonstrate a measurable effect of DBH-defined noradrenergic neuronal activity on respiratory control and/ or ventilatory response to $\mathrm{CO}_{2}$. If change was seen in room air, then basal respiratory control was affected by the change in activity of these neurons. If changes were seen in $5 \% \mathrm{CO}_{2}$, then changes in the activity of these neurons affected the hypercapnic ventilatory response. $\mathrm{DBH}$-Cre-defined NA neurons were inhibited by crossing mouse line $R R 1 P$ to $T g(D b h$ cre)KH212Gsat (TgDBH-Cre) mice. We observed no changes under room air conditions (Fig. 8A). However, under hypercapnic conditions, we saw a reduction in ventilation (Fig. 8B), with decreases in $V_{T}$ (tidal

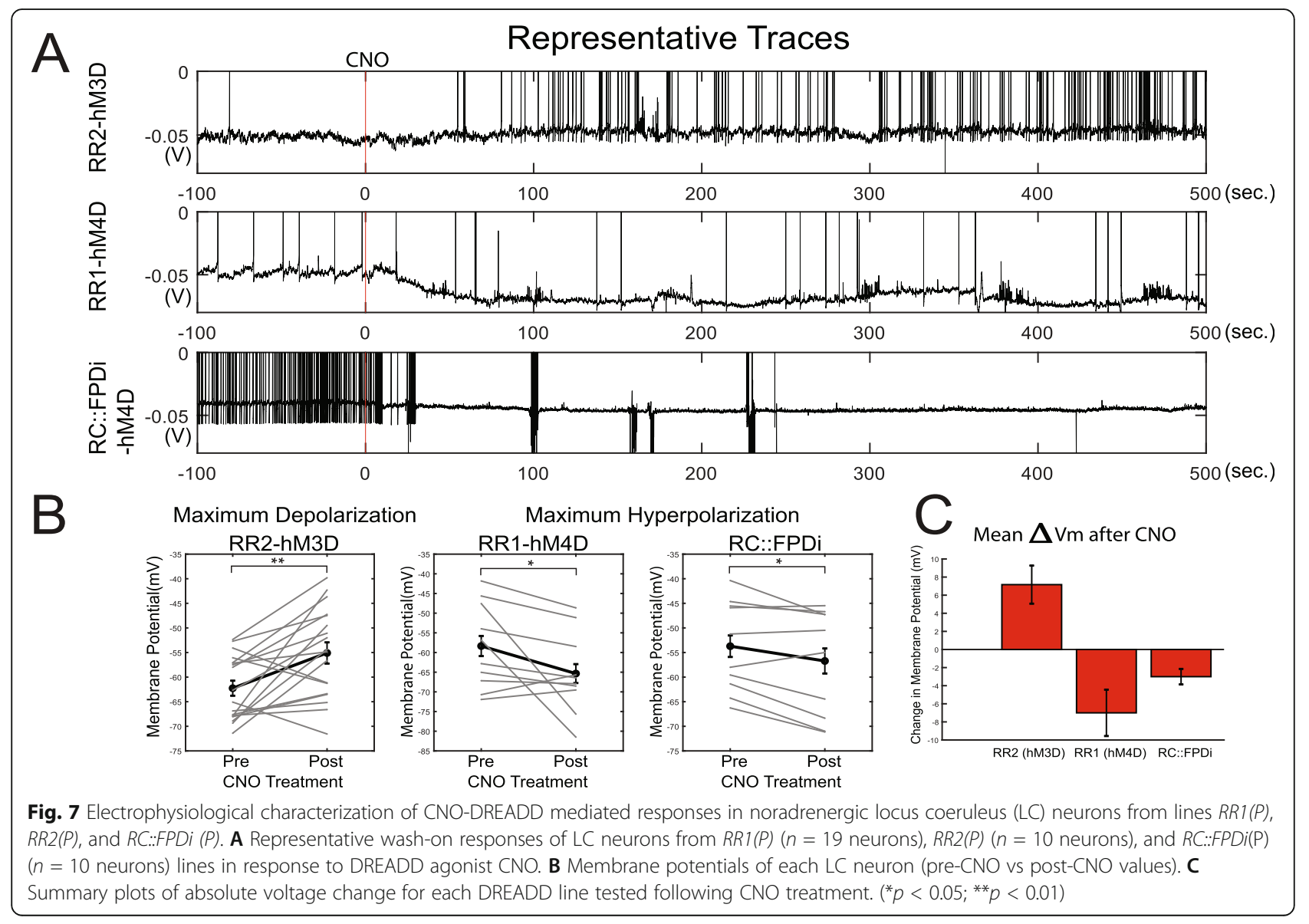




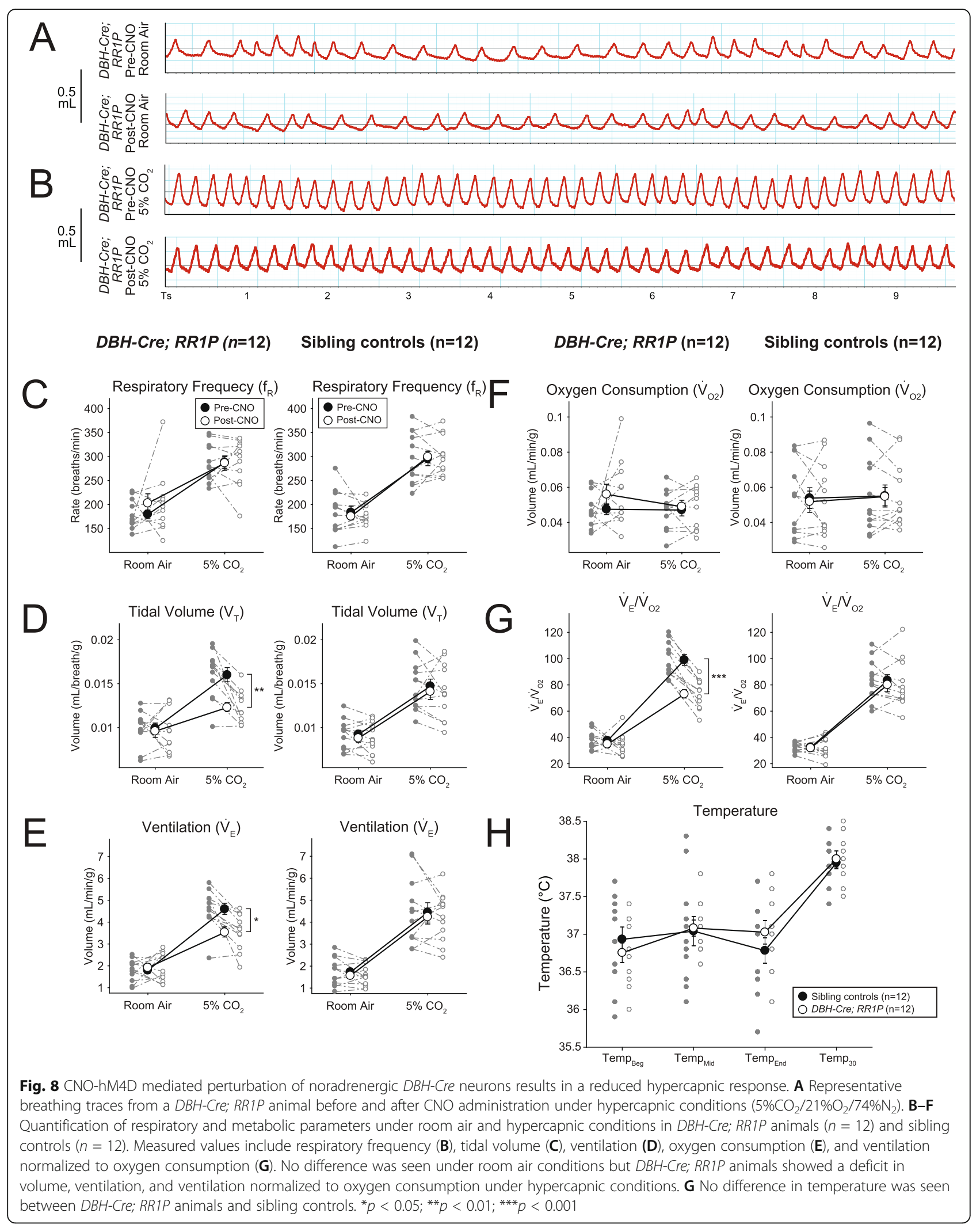


volume) $(-26.6 \%, p=0.0021$, Fig. $8 \mathrm{D}), \dot{V}_{\mathrm{E}}$ (ventilation) $(-26.8 \%, p=0.026$, Fig. $8 \mathrm{E})$, and $\dot{V}_{\mathrm{E}} / \dot{V}_{\mathrm{O} 2}$ (ventilatory equivalents for oxygen) (-28.7\%, $p<0.0001$, Fig. 8G). No significant differences were observed in body temperature between experimental animals and sibling controls (Fig. 8H). Notably, sibling controls showed no difference in respiratory parameters pre- and post-CNO administration. All raw data from these experiments are available on Zenodo (10.5281/zenodo.5781763).

We then tested the applicability of the $R R 2 P$ line in vivo. After CNO-DREADD-mediated stimulation of $D B H$-Cre-defined neurons, we saw significant increases under room air ventilation (Fig. $9 \mathrm{~A}$ ) in $f_{\mathrm{R}}$ (Respiratory frequency) (+28.1\%, $p=0.0076$, Fig. $9 \mathrm{C}), V_{T}(+43.3 \%$, $p=0.00077$, Fig. 9D), $\hat{V}_{E}(+83.6 \%, p<0.0001$, Fig. 9E), and $\dot{V}_{\mathrm{O} 2}$ (Oxygen consumption) (+50.9\%, $p<0.0001$, Fig. 9F). The increase in $\dot{V}_{\mathrm{E}}$ was proportional to the increase in $\dot{V}_{\mathrm{O} 2}$, however, so $\dot{V}_{\mathrm{E}} / \dot{V}_{\mathrm{O} 2}$ did not change (Fig. 9G). Under hypercapnic conditions, as compared to pre-CNO values, $\dot{V}_{\mathrm{O} 2}$ was increased $(+37.2 \%, p=$ 0.0015 , Fig. 9F), resulting in a reduced $\dot{V}_{\mathrm{E}} / \dot{V}_{\mathrm{O} 2}(-$ $24.2 \%, p=0.04$, Fig. 9G). We also observed a deficit in body temperature in $\mathrm{DBH}-\mathrm{Cre}$; $\mathrm{RR} 2 \mathrm{P}$ animals $30 \mathrm{~min}$ after the end of the assay at room temperature $(\sim 1.5 \mathrm{~h}$ after $\mathrm{CNO}$ injection) as compared to sibling controls (Fig. 9H), but not immediately at exit from the respiratory chamber, which is kept at a thermoneutral temperature, $30-32{ }^{\circ} \mathrm{C}$. Sibling controls showed no difference in respiratory parameters pre- or post-CNO administration. The respiratory phenotypes seen here clearly demonstrate an acute and cell-autonomous involvement of the whole NA system in $\mathrm{CO}_{2}$ chemosensitivity and baseline metabolism while avoiding the confounds of developmental compensatory events or off-target effects. All raw data from these experiments are available on Zenodo (10.5281/zenodo.5781775).

Finally, we characterized a fourth line, produced by oocyte CRISPR-mediated recombination to express the Twitch2B ratiometric calcium indicator upon Cre recombinase expression. Calcium signaling was recorded in outer granulosa cells surrounding an oocyte taken from a germline recombined (RR8; Bact_Cre) mouse line (Fig. 10A). Upon application of $10 \mu \mathrm{M}$ ionomycin in the presence of $10 \mathrm{mM} \mathrm{CaCl}_{2}$, the yellow fluorescent protein (YFP)/ cyan fluorescent protein (CFP) ratio increased more than 3-fold (Fig. 10B). The data demonstrate how the targeting system here can be used to build conditional mouse lines that are useful beyond the nervous system and throughout the body [67]. All raw data from these experiments are available on Zenodo (10.5281/zenodo.5781661).

Collectively, these data highlight how our single recombinase and intersectional lines can be used to functionally assess dispersed and difficult to access populations, setting the stage for further characterization and dissection of a variety of systems in a given measured outcome through intersectional subdivision by genetic or viral methods.

\section{Discussion}

\section{Vector design and optimization}

Our tricistronic mouse line vector (RR5) was a complex vector to design. Thus, the discussion of its construction applies to the other simpler vectors and best describes choices made to optimize the vectors. Our initial goal was to create an intersectional mouse strain expressing three fluorescent components to highlight the nucleus, whole neuron, and presynaptic contacts, enabling facile study of cell counts, cellular morphology, and axonal and projection targets (RR5 consisting of H2B-TagBFP, sfGFP, and synaptophysin-tdTomato separated by p2a elements) without the need for signal amplification using antibodies. However, likely due to the high number of repetitive elements in the Rosa26 3' homology arm and the high complexity and repetitive components of the intersectional cassette (i.e., two stop cassettes consisting of multiple SV40 polyadenylation sequences, tdTomato protein dimer, double loxP and FRT sites, and two p2a self-cleaving peptides separating the elements), we had no success in stably subcloning the intersectional cassette into a low copy vector (p15a ori) containing the original Rosa 26 homology arms (1.1 kb 5' homology arm and $4.2 \mathrm{~kb} 3^{\prime}$ homology arm) and DTA negative selection gene [52]. Thus, we sought to make several improvements on the prior approaches used to build intersectional genetic mice. First, we sought to stabilize the vector by shortening the homology arms and eliminating repetitive genomic elements found at the Rosa26 locus. Second, we removed the DTA negative selection terminal non-homology to eliminate the need to validate intersectional cassettes separately before placing the cassette in the targeting vector. Third, we reduced the size of the selection cassette. Prior intersectional constructs carried an additional PGK promoter and BGHpA tail for neomycin expression. We eliminated both promoter and BGHpA as the functions of these elements can easily be served by the CAG promoter and SV40pA in the stop cassette. With smaller homology arms, it was possible that our targeting efficiency would fall. Therefore, we introduced a CRISPR/Cas9 targeting strategy to enhance homologous recombination in either ES cells or oocytes. Surprisingly, in ES cells, the shorter homology arms performed equally well as the full-length homology arms (see "Discussion" below). The resulting strategy offered a simplified, smaller, and highly stable vector that remains efficient at targeting the Rosa26 locus. Through this optimization process, we built a set of baseline vectors 


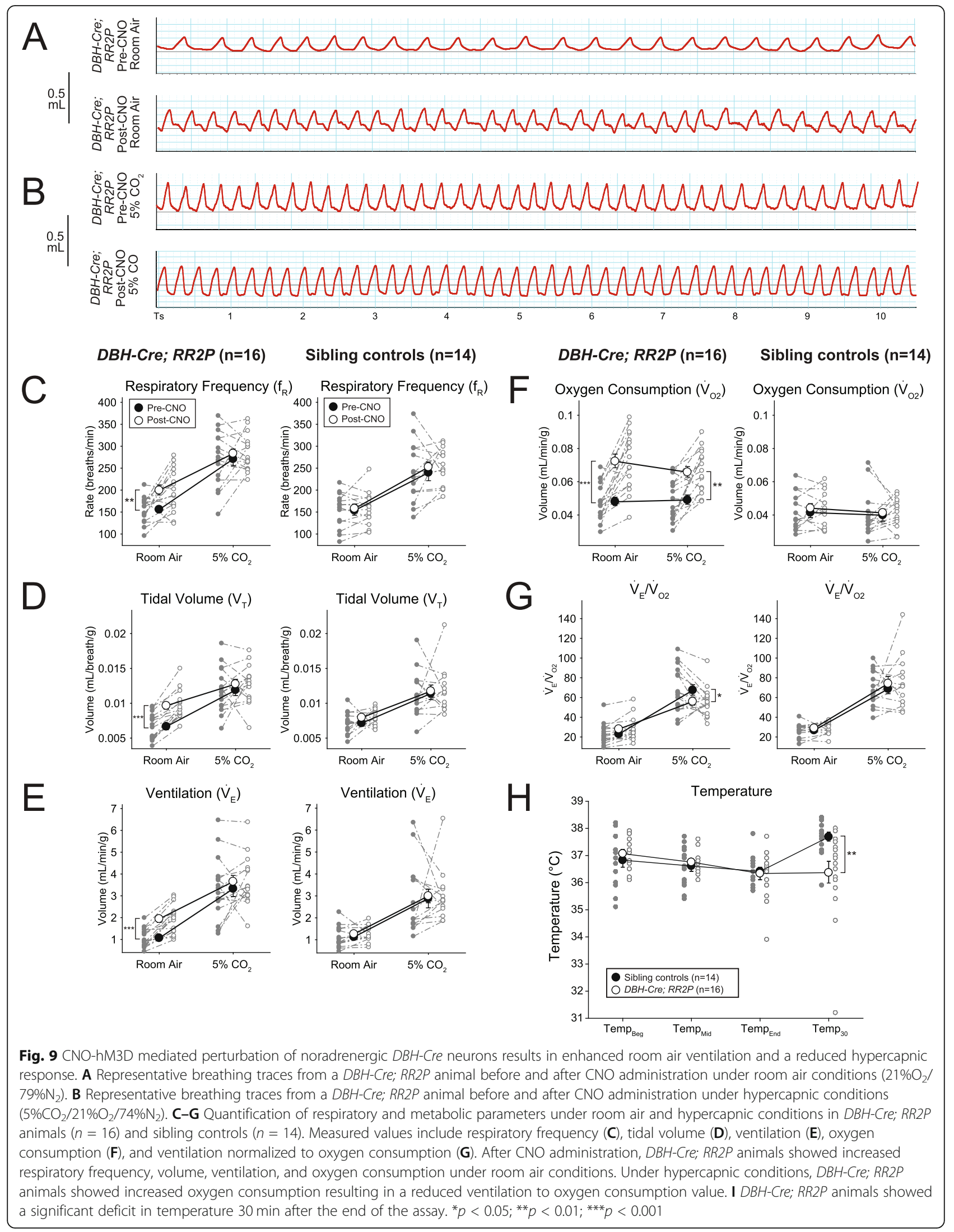



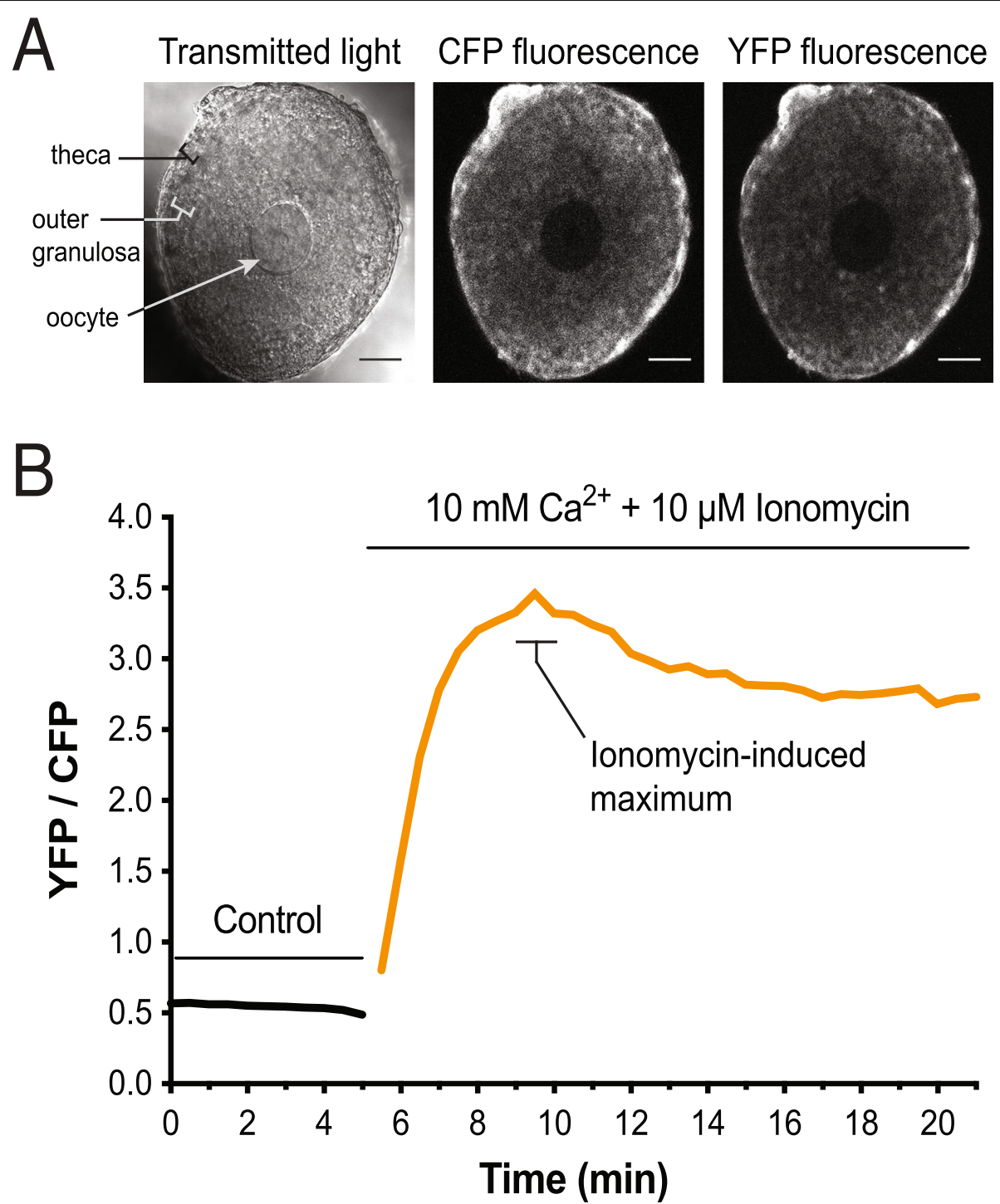

Fig. 10 Expression and function of Twitch-2B in the granulosa cells of mouse ovarian follicles. A A follicle from a mouse expressing Twitch-2B (homozygote). A follicle consists of multiple layers of granulosa cells surrounding an oocyte in the center. Twitch-2B is uniformly expressed in the granulosa cells but is not detectable in the oocyte. A layer of theca cells, adhering to the outside of the follicle, expresses Twitch-2B at a higher level. Scale bar $=50 \mu \mathrm{m}$. B 6-fold increase in YFP/CFP ratio in the outer granulosa cells after application of $10 \mu \mathrm{M}$ ionomycin in the presence of $10 \mathrm{mM} \mathrm{CaCl}_{2}$. Representative of $n=4$ follicles

that can be used to build any intersectional genetic targeting allele rapidly and inexpensively by simply cloning in a cDNA of interest into one or both of the multiple cloning sites for both intersectional and subtractive expression.

\section{Embryonic stem cell electroporation}

While CRISPR strategies are widespread for knockout mutations and small deletions and insertions in mouse zygotes, consistent knock-in of large targeting cassettes $(>4 \mathrm{~kb})$ still remains a challenge with fewer but increasing successes $[48,68,69]$. To address this limitation, our new multiplexed methodology enabled us to: (1) simplify our base targeting vector to less than $5 \mathrm{~kb}$ in total length; (2) see successful targeting of added cassettes up to 11 $\mathrm{kb}$; (3) increase the rate of targeting by 5-10 folds over previous Rosa26 targeting attempts (that used a significantly longer 3' homology arm) under our ES cell strain and conditions; and (4) further reduce cost by coelectroporating five different targeting vectors in a single ES cell electroporation that were easily resolved to produce new mouse lines. While targeting rates for the Rosa26 locus can vary greatly in the literature, we compare only to our own experiments, as significant variability in targeting efficiency from lab to lab or facility to facility can arise from the several factors in ES cell 
electroporation ranging from electroporation conditions (e.g., buffer ionic strength, adjuvants, field strength, field duration, field shape, square wave vs exponential decay) to culture conditions (ES cell strain and genetic background, feeder type, media composition, inclusion of LIF). Notably, when we co-electroporated a CRISPR/ Cas9 plasmid to facilitate targeting, there was a proportional increase in targeting efficiency despite reduced amounts of targeting vector (total DNA in the EP was capped at $18-20 \mu \mathrm{g}$ per EP). At the highest efficiencies, we could further subdivide the small amount of targeting vector across multiple plasmids, which allowed us to introduce and recover as many as five vectors in a single EP. This multiplexed approach significantly reduced the costs of mouse production via ES cells. With these goals met, multiplexed ES cell targeting enables the rapid and high-throughput production of intersectional alleles that can be readily distributed throughout the mouse research community for further studies.

\section{Oocyte targeting}

Oocyte injection was only attempted with one line, $R R 8$. Less than $1 \%$ of the embryos contained a properly targeted vector, which in our experience suggests that direct oocyte injection is not efficient. Future optimization and the development of new technologies may increase the efficiency of targeting for more rapid generation of transgenic mice; for example, a study showed $10-20 \%$ targeting of 8-11 kb cassettes to the Rosa26 locus in oocytes using longer homology arms, while another showed successful targeting of a 5.5-kb cassette into the Rosa26 locus in rats with co-injection of two ssDNA oligos $[69,70]$. As noted above, there can be significant variability in targeting across labs based upon a variety of factors including background strain (vs strain from which the homology arms are derived), the use of Cas9 mRNA or protein, and site of injection (pro-nucleus vs cytoplasm, single vs 2-cell stage). Thus, our outcomes here may reflect our core facility capabilities as much as inherent limitations in consistent Cas9-mediated oocyte targeting of large constructs. The successful outcomes here and in a prior publication demonstrate the use of the system to develop lines capable of functional imaging [67].

\section{Select mouse line characterization}

Intersectional expression of fluorescent proteins (FPs) has been used to great effect for anatomical characterizations of targeted neuron populations $[66,71]$. Characterizations aimed at counting or highlighting single cells or cell populations made with a single FP can be made difficult, however, in cases where cell, axon, or dendrite density (neuropil) is high. Usually, one or two FPs are deployed to either fill the cell or highlight specific features, which necessitates the use of multiple reporter alleles to clearly observe cell number, morphology, and projections. To ameliorate these issues, we sought to create a mouse line (RR5) that highlights three specific features in an intersectionally defined neuron. Overall, this novel three-color mouse line enables intersectional and simultaneous labeling of three subcellular compartments. The polycistronic fluorescent labeling cassette gives unambiguous cell counts and clear visualization of cell morphology, axonal projections, and synaptic contacts. The strength of expression of all three colors is likely due to the use of p2a elements, rather than internal ribosome entry site (IRES) elements, which cause expression level reduction. Reduced expression from an IRES may stem from cryptic splice elements in the IRES that could interact with the intron in the CAG promoter or splice acceptors in some stop cassettes [72]. Our use of $\mathrm{p} 2 \mathrm{a}$ appears to bypass those issues as all three fluorescent proteins could be readily visualized without additional enhancement as compared to other approaches [38].

We also show that combinations of germline, viral, and retrograde viral expression of recombinases in the $R R 5$ line can all be used to clearly map the shared innervation of multiple regions by a small subset of genetic, projection, and/ or intersectionally defined neurons. In contrast to prior intersectional studies using two genetic delimiters to define a subpopulation with a single fluorescent protein (with or without an inert retrograde marker injected into separate sites in the brain), our approach enables facile collateral mapping across the whole nervous system with higher resolution that is growing in popularity $[36,64,71]$. These results demonstrate that despite the high complexity and repetitive nature of the $R R 5$ cassette, we could efficiently target this allele, the allele remains stable through germline transmission, and it is responsive to Cre and FLP recombinase expression. The restriction of expression to anatomically defined NA neurons as a whole or as a projection subset further establishes the recombinase specificity of our targeting schematic. This approach should also translate equally well to further anatomical, functional, and molecular characterizations of NA and other subtypes defined by their projection patterns with the use of the additional lines reported here.

The outcomes of either inhibiting (RR1P; TgDBH_Cre) or stimulating (RR2P; $\left.T g D B H_{-} C r e\right)$ NA neurons as defined by $T g D B H \_C r e$ strongly support the functionality of these two lines in an in vivo setting. NA neurons are strongly implicated in control of respiratory homeostasis and chemosensitivity [8, 73-79]. Previous studies focused on demonstrating the role of NA neurons in breathing bear methodological caveats such as lack of resolution due to overly broad lesions or injections [80], 
developmental and non-cell-autonomous compensation after gene mutations, restraint or anesthesia in vivo, and they typically lack concurrent metabolic measurements ( $\dot{V}_{\mathrm{E}} / \dot{V}_{\mathrm{O}}$ ) [81]; thus, direct comparisons are difficult. Nonetheless, previous work has been reiterated in many ways with our results here in that focal pharmacological NA lesions decrease respiratory frequency and hypercapnic ventilatory response [75]. Here we show in conscious, unrestrained mice that inhibition of $\mathrm{TgDBH}$ Cre-defined noradrenergic neurons led to significantly reduced tidal volume, ventilation, and $\dot{V}_{\mathrm{E}} / \dot{V}_{\mathrm{O} 2}$ following hypercapnic exposure. On the other hand, activation of TgDBH_Cre-defined noradrenergic neurons led to significantly increased respiratory frequency, tidal volume, ventilation, $\dot{V}_{\mathrm{O} 2}$, and $\dot{V}_{\mathrm{E}} / \dot{V}_{\mathrm{O} 2}$ in the room air breathing condition. These changes likely stem from a combined increase in central and peripheral (sympathetic) outflow increasing overall metabolic rate $\left(V_{\mathrm{O} 2}\right)$. Although breathing and $\dot{V}_{\mathrm{O} 2}$ are both increased, a small but significant mismatch occurs in hypercapnia suggesting that global excitation may destabilize hypercapnic reflexes as well. Notably, after removal from the thermoneutral recording chamber, the body temperature dropped significantly. This drop is consistent with prior studies that show central NA outflow to the hypothalamus negatively regulates body temperature [82, 83]. The magnitude of changes seen for both stimulation and inhibition of $T g D B H \_C r e$ defined NA neurons in various breathing parameters, particularly for hypercapnia, is in line with expectations of a highly redundant chemosensory system in the respiratory network along with the fact that the NA system is neuromodulatory in nature [37, 52, 84-87]. Altogether, the numerous breathing, metabolic, and temperature changes observed support the functionality of these lines for in vivo chemogenetic manipulations. These data represent modulation of the noradrenergic system that, methodologically, significantly deviates from previously published studies interrogating this system and provides an alternative to those investigating control of breathing that reduces the influence of unintended effects.

In conclusion, the methods presented here represent a significant improvement in feasibility and affordability for labs to generate their own intersectional mouse models for application in a variety of fields. Our vector design and application allow for large cassettes to be targeted to the Rosa26 locus with high throughput, increased efficiency, germline transmission, and preserved pluripotency. These protocols and techniques can be used to investigate most, if not all, neural circuits in the context of development and/or disease. Implementing these techniques also serves as an alternative to costprohibitive commercially available vectors and mouse lines. Together, we present a facile, cost-effective method for producing gene-specific intersectional mouse lines.

\section{Conclusions}

During development, many distinct cellular subtypes arise and intercalate to create the complex cells, organs, and organ systems that constitute our behavior and physiology. Key to understanding this organization and how it may be perturbed in diseases is the ability to identify and access discrete cell subtypes in the developing and adult mouse for multifaceted studies. It is now clear that even within narrowly defined cell types once thought as homogeneous, significant diversity is found at multiple levels including genetic and molecular signatures, activity patterns, synaptic connectivity, and projection patterns. Given this complexity, it is often difficult to define and access specific cellular populations for study, particularly during embryogenesis, where in utero development makes access problematic. In neuroscience, the power of studying combinatorially defined neuronal populations increases significantly when multiple distinct neuronal features, such as birthdate, collateral projection targets, molecular profiles, or a functional requirement in a given physiological process or behavior can be examined in parallel to reveal deeper insights into the mechanisms involved in the establishment and maintenance of neural circuit organization. However, the ability to carry out such studies is restricted by the limited number of publicly available intersectional mouse lines as well as the inherent difficulty in developing new intersectional alleles.

We present a novel CRISPR/Cas9-mediated system for consistently targeting large cassettes to the Rosa26 locus for high-throughput and parallel generation of intersectional and conditional mouse lines. These studies demonstrate that CRISPR/Cas9 can be used to increase targeting efficiency at the Rosa26 locus in mouse embryonic stem cells with shortened 1-1.2-kb homology arms while preserving pluripotency and the ability to transmit alleles via the germline. This technology allows for the opportunity to generate mouse lines that express a wide range of effector molecules in various cell types, enabling the developmental, anatomical, molecular, and functional characterization of cellular organization in behavior and physiology. To democratize the generation of intersectional and conditional targeted ES cells and mouse lines, we have generated a publicly available vector toolkit for single-step cloning into Rosa26-targeting vectors for double and single recombinase-responsive cassettes (Table 1). We have also generated several mouse lines available, without restriction, to the not-forprofit research community enabling high specificity intersectional access of neuronal and other populations 
for cross correlative mapping approaches using functional neuronal perturbation, molecular profiling, and anatomical characterizations for multifaceted studies (Table 2). Overall, these resources and the modular nature of the intersectional approach make rapid and low-cost production of large numbers of intersectional alleles possible that can be efficiently distributed as ES cells or mouse lines throughout the mouse research community. All vectors (Addgene; 97007-97012, 99142), mouse lines (MMRRC; 043513-043519), and ES cells (BCM ES Cell Core Facility) have been made publicly and unconditionally available to the academic research community.

\section{Methods}

\section{Construction of targeting and Cas9 vectors}

The simplified Rosa26 targeting vector was derived using standard cloning procedures from a targeting vector used in previous studies [52] consisting of a p15a origin of replication, kanamycin selection cassette, DTA negative selection cassette, and Rosa26 homology (1081 bp 5' homology arm and 4342 bp 3' homology arm). The total vector size was $9084 \mathrm{bps}$. The DTA was removed and the $5^{\prime}$ homology arm was shortened to $1025 \mathrm{bp}$ fragment (deleting the sgRNA target sequence (chr6:113,076,062113,077,087 GRCm38/mm10)) while the 3' homology arm was shortened to $1231 \mathrm{bps}$ (chr6:113,074,801113,076,032 GRCm38/mm10), maintaining the insertion site within the first intron and reducing the total vector length to $4694 \mathrm{bps}$ and eliminating a number of repetitive regions that often resulted in vector instability when constructing intersectional targeting vectors.

For the Cas9 expressing vector, we selected an sgRNA target sequence that was close to the $5^{\prime}$ and $3^{\prime}$ junction of the Rosa26 gene locus (ACTGGAGTTGCAGATC ACGA with PAM motif GGG; chr6:113,076,040113,076,05 GRCm38/mm10). The selected sgRNA was cloned into the BbsI sites of the px330 vector that expresses Cas9 (final vector is called px330_Rosa26_ $\operatorname{sgRNA).}$

Knock-in cassettes were assembled in either (1) a previously used intersectional template plasmid (RR1-4, RR6-7 OL963770-OL963773; OL963775-OL963776); (2) a newly constructed intersectional template plasmid with neomycin promoter and $\mathrm{pA}$ elements removed (RR5 and $R R$ 9, OL963774; OL963778); (3) a Cre-only derivative of the newly constructed intersectional template plasmid with neomycin promoter and $\mathrm{pA}$ elements removed (RR8, OL963777); or (4) a constructed Dre-responsive template plasmid (RR10 and RR11 OL963779; OL963780). The intersectional plasmid consisted of a ubiquitous $C A G$ promoter sequence; an $F R T$-flanked stop cassette consisting of a PGK-neo sequence (for positive selection of targeted ES cells) and three SV4O $p A$ sequences; a LoxP-flanked stop cassette containing mCherry and a PBS302 stop cassette; and a cloning site for insertion followed by a WPRE and BGHpA sequence. The new intersectional template consisted of a ubiquitous $C A G$ promoter sequence; an $F R T$-flanked stop cassette consisting of a neomycin sequence and His3_SV4O $p A$; a LoxP-flanked subtractive cloning site stop cassette consisting of a His3_SV4O pA; and a cloning site for insertion followed by WPRE and BGHpA sequences. The Dre-responsive template consisted of a Rox-flanked stop cassette consisting of a neomycin sequence and PBS302 stop cassette, and a cloning site followed by a WPRE and $B G H p A$ sequence.

For assembly of complete targeting vectors, the cDNAs of interest were PCR amplified and cloned into the corresponding vector. The intersectional or Dre-responsive cassettes were then cut out with PacI or PacI/AscI and cloned into the shortened Rosa26 targeting vector.

To facilitate single-step cloning of complete targeting vectors, we generated a vector toolkit (Table 1) by constructing and moving empty $C A G$ cassettes in the Rosa26 targeting vector. We generated four template vectors with neomycin resistance: (1) a Cre/FLP-responsive targeting vector; (2) Cre only; (3) FLP only; and (4) Dre-responsive targeting vector. The intersectional template vector consists of the $C A G$ promoter, an $F R T$ flanked neomycin resistance gene and stop cassette, a subtractive cloning site (EcoRV) and stop cassette flanked by $\operatorname{LoxP}$ sites, an intersectional cloning site (PmeI), and WPRE and BHGpA elements. Each single template vector consists of the $C A G$ promoter, stop cassette(s) and neomycin resistance cassette flanked by recombinase sites, cloning site (SwaI), and WPRE and bgh polyA elements. Additionally, for possible direct oocyte injections, we also generated a Cre/FLP-responsive targeting vector that does not contain a neomycin resistance gene, with a subtractive cloning site (EcoRV) and intersectional cloning site (SwaI). All cloning sites are blunt restriction enzyme sites for cloning facilitation. Sequences of the template vectors and $p \times 330$ vector and plasmids are available through Addgene (ID \#s 9700797012, 99142).

\section{Generation of knock-in mice}

Embryonic stem (ES) cells (AB2.2) were electroporated with $15-20 \mu \mathrm{g}$ of varying ratios of the px330_Rosa26_sgRNA vector to the targeting vector. Neomycin selected clones were screened for homologous recombination using PCR genotyping. Targeted clones were identified using PCR genotyping for $5^{\prime}$ and $3^{\prime}$ targeting from outside the homology arm and were considered to be successful targeting events if positive for both $5^{\prime}$ and 3 ' genotyping. We used pairs 5'CGCCTAAAGAAGAGGCTGTG (Rosa26-F) and 5'GGGCGTACTTGGCATATGAT (CAG-R), producing a 
$1450 \mathrm{bp}$ band; and 5'AATCAACCTCTGGATTACAAAATTT (WPRE-F) and 5'TGGCTCCTCTGTCCACAGTT (Rosa26-R), producing a 2472-bp band. Select targeted clones were microinjected into C57B1/J6 blastocysts and chimeric males were bred to wildtype C57B1/J6 females to achieve germline transmission.

\section{Pronuclear injection}

We constructed a targeting vector by cloning a calcium indicator, Twitch-2B [55], into the Cre-responsive Rosa26 targeting vector. The Baylor College of Medicine Embryonic Stem (ES) Cell Core generated the Rosa26specific sgRNA and Cas9 protein for injection. Pronuclear injections were performed by the Baylor College of Medicine Genetically Engineered Mouse (GEM) Core using the following parameters: $30 \mathrm{ng} / \mu \mathrm{l}$ Cas 9 protein, $20 \mathrm{ng} / \mu \mathrm{l} \mathrm{sgRNA}$, and $2 \mathrm{ng} / \mu \mathrm{l}$ dsDNA plasmid. Potential founders were screened for targeting as described above.

\section{Breeding, genetic background, and maintenance of mice}

We maintained colonies of select mouse strains by backcrossing to $\mathrm{C} 57 \mathrm{BL} / 6 \mathrm{~J}$ mice. For routine genotyping, we carried out PCR amplification of DNA from ear punch preparations using the boiling alkaline lysis procedure. Rosa26-specific primers for the mice were 5'-GCACTT GCTCTCCCAAAGTC, 5'-GGGCGTACTTGGCATA TGAT, and 5'-CTTTAAGCCTGCCCAGAAGA, and yield a 495-bp band (targeted) and 330-bp band (wildtype). For histology experiments, $R R 5$ mice were bred to DBH ${ }^{p 2 a F L P o}$ [54]; B6N.FVB-Tmem163 ${ }^{T g(A C T B-c r e) 2 M r t} / C j D s w$ $J$ (Bactin-Cre) and DBH ${ }^{p a F L P o}$ mice. For plethysmography experiments, B6.FVB(Cg)-Tg(Dbh-Cre)KH212Gsat/Mmucd (DBH-Cre) mice were mated with homozygous Cre-onlyresponsive $R R 1 P$ and $R R 2 P$ mice (after crossing intersectional alleles to B6;SLL-Tg(ACTFLPe)9205Dym/J [JAX 003800] mice to recombine out the FLP-responsive stop cassette followed by homozygosity) to derive animals in which all mice carried the Cre-responsive hM4D or hM3D allele. Sibling animals that did not inherit the Cre allele were used as control animals to the Cre-positive offspring. For electrophysiology experiments, $\mathrm{DBH}$-Cre; RR2P mice were mated to $R C:: e P e$ mice expressing a floxed eGFCrespecific primers were $5^{\prime}$-ATCGCCATCTTCCAGCAGGC GCACCATTGCCC and 5'-GCATTTCTGGGGATTGCT TA and yielded a 550-bp band if positive. FLPo-specific primers were $5^{\prime}$ CACGCCCAGGTACTTGTTCT and 5' CCACAGCAAGAAGATGCTGA and yielded a $226 \mathrm{bp}$ band if positive.

Established mouse lines reside at the Mutant Mouse Regional Resource Center (MMRRC) and will be unconditionally available to the academic research community (MMRRC 043513-043519). Targeted ES cells have been archived and are available upon request under the condition that any new mouse lines are deposited in a public repository.

All animal experiments were performed with the approval of IACUC.

\section{Off-target analysis}

Off-target sequences were identified using the Optimized CRISPR Design tool (crispr.mit.edu). The top 5 sequences for each sgRNA were amplified from selected targeted ES cells and sequenced to determine if any mutations or changes occurred in off-target sites.

\section{Viral injection}

To test the functionality of the RR5 mouse strain, adult $R R 5$ mice were injected with equal titers of AAV9-hSynFLPo and AAV1-hSyn-Cre viruses (obtained from $M$. Xue at BCM, $250 \mathrm{nl}$ at $1.12 \times 10^{12} \mathrm{GC} / \mathrm{mL}$ ) into the dentate gyrus (coordinates from bregma $\mathrm{AP}=-2.70$, $\mathrm{DV}=-2.12, \mathrm{ML}=1.84)$ and with equal titers of AAVEF1a-Cre-WPRE and AAV-EF1a-FLPo-WPRE (UNC Vector Core, $250 \mathrm{nl}$ at $5.06 \times 10^{11} \mathrm{GC} / \mathrm{mL}$ ) into the amygdala (coordinates from bregma $\mathrm{AP}=-1.06, \mathrm{DV}=$ - 4.61, $\mathrm{ML}=-2.86$ ) and allowed to incubate for 7-14 days. For expression in the olfactory bulb, adult $R R 5$ mice were injected with AAV-CAG-Cre (obtained from Neuroconnectivity Core at Jan and Dan Duncan Neurological Research Institute, AAV2/9 $690 \mu \mathrm{L}$ at $5.37 \times 10^{13}$ $\mathrm{pp} / \mathrm{mL}$ ) and AAV-Ef1a-Flp (obtained from Neuroconnectivity Core at Jan and Dan Duncan Neurological Research Institute, AAV2/9 $690 \mu \mathrm{L}$ at $\left.7.16 \times 10^{11} \mathrm{pp} / \mathrm{mL}\right)$ into the core of the olfactory bulb (coordinates from bregma $\mathrm{AP}=4.5 \mathrm{~mm}, \mathrm{DV}=-2.25 \mathrm{~mm}, \mathrm{ML}= \pm 0.8$ $\mathrm{mm})$ and allowed to incubate for 14 days. For the CAV2-Cre virus experiments, RR5; DBH $H^{\text {p2aFLP }}$ mice were injected with CAV2-Cre virus (IGMM Viral Core, $500 \mathrm{~nL}$ at $6.0 \times 10^{12} \mathrm{pp} / \mathrm{mL}$ ) into the amygdala (coordinates $\mathrm{AP}=-2.86, \mathrm{DV}=-1.06, \mathrm{ML}=-4.61)$ and allowed to incubate for 17 days. For the Retro-AAVEf1a-FLPo virus experiments, RR5; Vglut2_Cre mice were injected with Retro-FLPo virus (obtained from Neuroconnectivity Core at Jan and Dan Duncan Neurological Research Institute, $690 \mu \mathrm{L}$ at $\left.1.49 \times 10^{12} \mathrm{pp} / \mathrm{mL}\right)$ into the lateral hypothalamic area (coordinates from bregma $\mathrm{AP}=-1.22 \mathrm{~mm}, \mathrm{DV}=-5.12 \mathrm{~mm}, \mathrm{ML}= \pm$ $0.97 \mathrm{~mm}$ ) and allowed to incubate for 21 days.

\section{Histology}

For RR5 expression, animals were sacrificed and transcardially perfused with $0.1 \mathrm{M}$ phosphate-buffered saline (PBS) then with $4 \%$ paraformaldehyde (PFA) in PBS. Brains were dissected out and drop fixed for $2 \mathrm{~h}$ in $4 \%$ PFA before a PBS rinse and equilibration in $20 \%$ sucrose in PBS. Brains were sectioned into $30-40-\mu \mathrm{m}$ coronal sections and mounted on slides. Images were collected 
on a Zeiss confocal LSM780 microscope or Leica TCS SPE confocal microscope.

\section{Electrophysiology Slice preparation}

Slice preparation from the mouse LC follows an $\mathrm{N}$-Methyl-D-glucamine (NMDG) slicing protocol [88, 89]. Briefly, animals were deeply anesthetized using 3\% isoflurane. After decapitation, the brain was removed and placed into cold $\left(0-4{ }^{\circ} \mathrm{C}\right)$ oxygenated NMDG solution containing $93 \mathrm{mM}$ NMDG, $93 \mathrm{mM} \mathrm{HCl}, 2.5 \mathrm{mM} \mathrm{KCl}$, $1.2 \mathrm{mM} \mathrm{NaH}_{2} \mathrm{PO}_{4}, 30 \mathrm{mM} \mathrm{NaHCO}_{3}, 20 \mathrm{mM}$ HEPES, 25 $\mathrm{mM}$ glucose, $5 \mathrm{mM}$ sodium ascorbate, $2 \mathrm{mM}$ Thiourea, $3 \mathrm{mM}$ sodium pyruvate, $10 \mathrm{mM} \mathrm{MgSO}_{4}$, and $0.5 \mathrm{mM}$ $\mathrm{CaCl}_{2}$, pH 7.35 (all from SIGMA-ALDRICH). Horizontal slices were prepared using a vibratome $(200 \mu \mathrm{m}$ thick) using zirconia blades. The brain slices were kept at 37.0 $\pm 0.5^{\circ} \mathrm{C}$ in oxygenated NMDG solution for $10 \mathrm{~min}$. They were then transferred to an artificial cerebrospinal fluid (ACSF) containing $125 \mathrm{mM} \mathrm{NaCl}, 2.5 \mathrm{mM} \mathrm{KCl}, 1.25 \mathrm{mM}$ $\mathrm{NaH}_{2} \mathrm{PO}_{4}, 25 \mathrm{mM} \mathrm{NaHCO} 3,1 \mathrm{mM} \mathrm{MgCl}, 25 \mathrm{mM}$ glucose, and $2 \mathrm{mM} \mathrm{CaCl} 2$ ( $\mathrm{pH}$ 7.4) for at least $1 \mathrm{~h}$ prior to the beginning of recordings. During the recording sessions, the slices were submerged in a commercially available chamber (Luig Neumann, Order No. 200-100 500 0150-M) and were stabilized with a fine nylon net attached to a custom-designed platinum ring. This recording chamber was continuously perfused with oxygenated physiological solution throughout the recording session.

\section{Recordings}

Whole-cell recordings were performed as described previously [89-91]. Briefly, patch pipettes (2-7 $M \Omega$ ) were filled with an internal solution containing $120 \mathrm{mM}$ potassium gluconate, $10 \mathrm{mM}$ HEPES, $4 \mathrm{mM} \mathrm{KCl}, 4 \mathrm{mM}$ MgATP, $0.3 \mathrm{mM} \mathrm{Na} \mathrm{N}_{3} \mathrm{GTP}, 10 \mathrm{mM}$ sodium phosphocreatine, and $0.5 \%$ biocytin ( $\mathrm{pH} 7.25)$. Whole-cell recordings from up to $8 \mathrm{LC}$ neurons were performed using two Quadro EPC 10 amplifiers (HEKA Electronic, Germany). PatchMaster (HEKA) and custom-written Matlab-based programs (Mathworks) were used to operate the recording system and perform online and offline data analysis. In current-clamp recordings, neurons were first current clamped at $\sim-40 \mathrm{pA}$ to prevent spontaneous firing. Prior to investigating the effect of drugs, we calculated spike thresholds and recorded firing patterns in response to sustained depolarizing currents by injecting increasing current steps $(+10 \mathrm{pA})$. Continuous recordings were obtained from LC neurons current clamped at - 40 to $0 \mathrm{pA}$ during drug wash-on experiments. We also calculated other intrinsic electrophysiological parameters, such as the input resistance, membrane time constant, spike amplitude, and after-hyperpolarization (AHP) [89-91].

\section{Plethysmography}

Plethysmography on conscious, unrestrained mice was carried out as described on 6-12-week-old adult animals with at least 12 animals in both the experimental and control group for a given experiment [52, 87]. Mice were subjected to a 5-day habituation protocol with each day consisting of several minutes of handling, temperature taken by rectal probe, intraperitoneal saline injection, and $30 \mathrm{~min}$ in the plethysmography chamber. Mice were then tested within 1 week of the last day of conditioning.

On the day of testing, mice were taken from their home cage and weighed, and rectal temperature was taken. Animals were then placed into an airtight, temperaturecontrolled $\left(\sim 32^{\circ} \mathrm{C}\right)$ plethysmography chamber and allowed to acclimate for at least $20 \mathrm{~min}$ in room air $\left(21 \% \mathrm{O}_{2} / 79 \%\right.$ $\mathrm{N}_{2}$ ) conditions. After acclimation and measurement under room air, the chamber gas was switched to a hypercapnic mixture of $5 \% \mathrm{CO}_{2} / 21 \% \mathrm{O}_{2} / 74 \% \mathrm{~N}_{2}$ for $20 \mathrm{~min}$. Chamber gas was then switched back to room air for $20 \mathrm{~min}$. The mice were briefly removed for rectal temperature measurement and intraperitoneal injection of clozapine- $\mathrm{N}$-oxide (CNO, National Institute of Mental Health Chemical Synthesis and Drug Supply Program) dissolved in saline (0.1 $\mathrm{mg} / \mathrm{mL}$ ) for an effective concentration $1 \mathrm{mg} / \mathrm{kg}$. The animal was returned to the chamber for another $20 \mathrm{~min}$ of room air, $20 \mathrm{~min}$ of hypercapnia, and $20 \mathrm{~min}$ of room air. The animal was then removed from the chamber and rectal temperature was taken immediately afterwards and again $30 \mathrm{~min}$ after the termination of the experiment. The animal was placed in its own cage during these $30 \mathrm{~min}$ at the ambient room temperature $\left(\sim 23^{\circ} \mathrm{C}\right)$.

\section{Plethysmography data collection and analysis}

Plethysmography pressure changes were measured using a Validyne DP45 differential pressure transducer and CD15 carrier demodulator in comparison to a reference chamber and recorded with LabChart Pro in real time. Waveforms were analyzed offline using LabChart Pro and custom-written MATLAB code (hosted on Zenodo 10.5281/zenodo.5768587) to determine respiratory frequency $\left(f_{\mathrm{R}}\right)$, tidal volume $\left(V_{\mathrm{T}}\right)$ [52], ventilation $\left(\dot{V}_{\mathrm{E}}\right)$, oxygen consumption $\left(\dot{V}_{\mathrm{O} 2}\right)$, ventilatory equivalents for oxygen $\left(\hat{V}_{\mathrm{E}} / \hat{V}_{\mathrm{O} 2}\right)$, and pattern analysis. Respiratory waveforms were collected offline during periods when the animal was at rest and readings were free from movement artifacts. A minimum of 1-min cumulative data compiled from traces at least $10 \mathrm{~s}$ long from the last $10 \mathrm{~min}$ of a given experimental condition were analyzed. $\mathrm{O}_{2}$ consumption was determined by comparing the gas composition between calibration in an empty chamber and live breathing using an AEI oxygen sensor and analyzer. Chamber temperature was constantly monitored and recorded using a ThermoWorks MicroThermo 2 with probe and was recorded with LabChart Pro in real time. 


\section{Plethysmography statistics}

Results $\left(f_{\mathrm{R}}, V_{\mathrm{T}}, \dot{V}_{\mathrm{E}}, \dot{V}_{\mathrm{O} 2}, \dot{V}_{\mathrm{E}} / \dot{V}_{\mathrm{O} 2}\right)$ for room air and hypercapnic data were compared between all cohorts using a linear mixed-effects regression model with animal type (experimental or control) and $\mathrm{CNO}$ administration (preor post-injection) as fixed effects and animal ID as a random effect. Temperature data was compared using a linear mixed-effects regression model with animal type (experimental or control) as a fixed effect. Residuals were independent and identically distributed as a normal distribution, which matches our model assumptions (Additional Files 3-5: Fig. S3-5). The residual plot for ventilatory equivalents of oxygen in room air for hM4D (Fig. 8) shows a slightly different distribution pattern (Additional File 4: Fig. S4). However, this is because the random effect coefficients are unusually small. This data still follows the normal and independent residuals assumption. Random effect coefficient distribution is not as easily assessed with so few datapoints and is not critical to statistical outcome if violated [92]. The $p$ values reported correspond to statistical significance of the conditional interaction between animal type and $\mathrm{CNO}$ administration. A $p$ value of $<0.05$ was used to indicate statistical significance and standard error of the mean is shown on all charts.

\section{Imaging of Twitch $\mathbf{2}$ in mouse preovulatory follicles}

Preovulatory follicles were isolated and imaged as previously described [93]. Briefly, antral follicles were dissected from 23- to 26-day-old RR8; Bact_Cre mice. Follicles were cultured for 24-30 h on organotypic membranes (Millipore; cat. No. PICMORG50) in the presence of follicle-stimulating hormone. The follicle was held in a perfusion slide consisting of a plastic slide (ibidi) and a glass coverslip and assembled using silicon grease. The slide was constructed such that medium containing ovine LH (National Hormone and Peptide Program; $10 \mu \mathrm{g} / \mathrm{mL}$ ) could be perfused through a $200-\mu \mathrm{m}$-deep channel holding the follicle. Temperature was maintained at $30-34{ }^{\circ} \mathrm{C}$, by use of a warm air blower (Nevtek). Preovulatory Follicles were imaged using a Zeiss Pascal confocal microscope with a $\times 40 / 1.2$ NA objective. Images were collected every $10 \mathrm{~s}$. Measurements were corrected for autofluorescence and for spectral bleed-through of CFP into the YFP channel. Ratios were calculated by dividing the mean CFP intensity in each region of interest by the mean YFP intensity. Data analysis was done using ImageJ and Excel software. Data is representative of 4 follicles.

\section{Abbreviations}

AAVs: Adeno-associated viruses; BGHpA: Bovine growth hormone polyA; cas9: CRISPR-associated protein 9; CAV2: Canine adenovirus 2; CFP: Cyan fluorescent protein; CNO: Clozapine-N-oxide; Cre: P1 bacteriophage cyclization recombinase gene; CRISPR: Clustered regularly interspaced short palindromic repeats; DAPI: 4'-6-Diamidino-2-phenylindole;
DBH: Dopamine beta-hydroxylase; Dre: D6 recombination system; DREADD: Designer receptor activated by designer drug; DTA: Diphtheria toxin A; eGFP: Enhanced green fluorescent protein; EP: Electroporation; ES: Embryonic stem; FLP: Flippase; FPs: Fluorescent proteins; FRT: FLP recombinase target; $f_{\mathrm{R}}$ : Respiratory frequency; $\mathrm{FSH}$ : Follicle-stimulating hormone; H2B-TagBFP: Histone 2B-tagged with blue fluorescent protein; HDR: Homology-directed repair; hM3D: Human M3 muscarinic receptor; hM4D: Human M4 muscarinic receptor; in/dels: Insertions/ deletions; IRES: Internal ribosome entry site; LC: Locus coeruleus; LH: Luteinizing hormone; loxP: Locus of crossover in P1; MMRRC: Mutant Mouse Regional Resource Center; NA: Noradrenergic; NMDG: N-methyl-Dglucamine; P: Postnatal day; p2A: Self-cleaving peptide derived from porcine teschovirus-1 targeting 2A; pA: Polyadenylation; PBS: Phosphatebuffered saline; PFA: Paraformaldehyde; PGK: 3-Phosphoglycerate kinase; PSAM: Pharmacologically selective actuator module; Rs: RASSL; sfGFP: Superfolder GFP; sgRNA: Single-guide RNA; ssDNA: Single-stranded DNA; tRNA: Transfer RNA; $\dot{V}_{E}$ : Ventilation; $\dot{V}_{E} / \dot{V}_{O_{2}}$ : Ventilatory equivalents for oxygen; Vgat: Vesicular GABA transporter; Vglut2: Vesicular glutamate transporter $2 ; \dot{V}_{\mathrm{O}_{2}}$ : Oxygen consumption; $V_{\mathrm{T}}$ : Tidal volume;

WHV: Woodchuck hepatitis virus; WPRE: WHV posttranscriptional regulatory element; YFP: Yellow fluorescent protein

\section{Supplementary Information}

The online version contains supplementary material available at https://doi. org/10.1186/s12915-022-01227-0.

Additional file 1: Figure S1. Genetic schema for animals used to gather data for Figures 3 and 4. Vector diagrams for the transgenes present in mice used for anatomical fluorescence experiments in Figures 3 and 4 . Demonstration of source of recombinase for animals from each panel in the figures.

Additional file 2: Figure S2. Breeding schema for animals used in Figures 7-9. Vector diagrams for animals used in e-physiology and whole animal physiology studies in Figures 7-9. Breeding paradigms indicated with arrows show recombinase and effector molecule source during derivation of used lines.

Additional file 3: Figure S3. QQplots for normal distribution testing of residuals from plethysmography analyses from Fig. 8. Plot of the empirical quantiles of the residual distributions vs the theoretical quantiles of gaussian distributions.

Additional file 4: Figure S4. Residual plots for independence testing of residuals from plethysmography analyses from Fig. 8 . Description of data: Plot of residuals vs model predicted values of the dependent variable.

Additional file 5: Figure S5. QQplots for normal distribution testing of residuals from plethysmography analyses from Fig. 9. Plot of the empirical quantiles of the residual distributions vs the theoretical quantiles of gaussian distributions.

Additional file 6: Figure S6. Residual plots for independence testing of residuals from plethysmography analyses from Fig. 9. Description of data: Plot of residuals vs model predicted values of the dependent variable.

\section{Acknowledgements}

We thank M. Xue for providing the Cre and FLPO AAV viruses used in the dentate gyrus injection and Ronda Kram for technical assistance with cloning, mouse husbandry, and maintenance. We thank J. Dougherty, E. Schuman, J. Wess, B. Roth, and S. Sternson for providing plasmid templates for the EGFP-L10A, MetRS, $G_{s}-D, h M 4 D$ and hM3D, and PSAM CDNA, respectively. We thank Laurinda A. Jaffe for collaborating with us and author JRE with the Twitch studies. The Baylor College of Medicine Embryonic Stem (ES) Cell Core performed the ES cell electroporations and were exceptionally helpful in our experiments and the Baylor College of Medicine Genetically Engineered Mouse (GEM) Core performed the blastocyst injections. Imaging was carried out at the Baylor College of Medicine Optical Imaging and Vital Microscopy Core.

\section{Authors' contributions}

SJL completed experiments, analyzed data, and prepared the manuscript. AM completed experiments, analyzed data, and prepared the manuscript. 
PJH completed experiments, analyzed data, and prepared the manuscript. PGF completed experiments, analyzed data and prepared the manuscript. JP completed experiments, analyzed data, and prepared the manuscript. AC completed statistical analyses and interpretations and prepared the manuscript. JJS completed experiments, analyzed data, and prepared the manuscript. VKM assisted in the completion of experiments. PJZ completed experiments, analyzed data and prepared the manuscript. JRE completed experiments, analyzed data, and prepared the manuscript. GA statistical analyses and interpretations and prepared the manuscript. XJ completed experiments, analyzed data, and prepared the manuscript. BRA completed experiments, analyzed data, and prepared the manuscript. AST completed experiments, analyzed data and prepared the manuscript. M C-M assisted with experimental design and prepared the manuscript. RR conceptualized the study, performed experiments, analyzed data, and prepared the manuscript. All authors read and approved the final manuscript.

\section{Funding}

R01: H1130249 (RR)

R21: OD025327 (RR)

R37: HD014939 (JRE and Laurinda A. Jaffe)

\section{Availability of data and materials}

All datasets, animals, and materials generated and/ or used in this study are publicly available (Addgene and GenBank, the Mutant Mouse Resource and Research Centers Supported by NIH (MMRRC)), or available from the corresponding author on reasonable request. All data generated or analyzed during this study are included in this published article and supplementary information files. Specifically, raw data can be found on Zenodo for electrophysiology experiments resulting in Fig. 7 (10.5281/zenodo.5794197), physiology experiments resulting in Fig. 8 (10.5281/zenodo.5781763) and 9 (10.5281/zenodo.5781775), and calcium imaging resulting in Fig. 10 (10.5281/ zenodo.5781661). The custom Matlab code for graph generation and statistical analyses can also be found on Zenodo (10.5281/zenodo.5768587).

\section{Declarations}

\section{Ethics approval and consent to participate}

All experiments reported herein were conducted with explicit approval of and oversight by both Baylor College of Medicine Institutional Animal Care and Use Committee (IACUC) and University of Connecticut IACUC and abide by all state and national regulations regarding animal research for each work site.

\section{Consent for publication}

Not applicable.

\section{Competing interests}

The authors declare that they have no competing interests.

\section{Author details}

${ }^{1}$ Department of Neuroscience, Baylor College of Medicine, Houston, TX, USA. ${ }^{2}$ Department of Molecular and Human Genetics, Baylor College of Medicine, Houston, TX, USA. ${ }^{3}$ Department of Statistics, Rice University, Houston, TX, USA. ${ }^{4}$ Department of Pharmacology, Baylor College of Medicine, Houston, TX, USA. ${ }^{5}$ Department of Cell Biology, University of Connecticut, Farmington, CT, USA. ${ }^{6}$ Department of Statistics, Computer Science, and Electrical and Computer Engineering, Rice University, Houston, TX, USA. ${ }^{7}$ Neurological Research Institute, Baylor College of Medicine, Houston, TX, USA. ${ }^{8}$ McNair Medical Institute, Houston, TX, USA.

\section{Received: 25 April 2021 Accepted: 6 January 2022}

\section{Published online: 28 January 2022}

\section{References}

1. Armbruster BN, Li X, Pausch MH, Herlitze S, Roth BL. Evolving the lock to fit the key to create a family of $\mathrm{G}$ protein-coupled receptors potently activated by an inert ligand. Proc Natl Acad Sci USA. 2007;104(12):5163-8. https://doi. org/10.1073/pnas.0700293104.

2. Sauer B. Manipulation of transgenes by site-specific recombination: use of cre recombinase: Guide to techniques in mouse development. Elsevier; 1993. p. 890-900. https://doi.org/10.1016/0076-6879(93)25056-8.
3. Chuong AS, Miri ML, Busskamp V, Matthews GAC, Acker LC, Sørensen AT, et al. Noninvasive optical inhibition with a red-shifted microbial rhodopsin Nat Neurosci. 2014;17(8):1123-9. https://doi.org/10.1038/nn.3752.

4. Rowitch DH, S-Jacques B, Lee SM, Flax JD, Snyder EY, McMahon AP. Sonic hedgehog regulates proliferation and inhibits differentiation of CNS precursor cells. J Neurosci. 1999;19(20):8954-65. https://doi.org/10.1523/ JNEUROSCI.19-20-08954.1999.

5. Urlinger S, Baron U, Thellmann M, Hasan MT, Bujard H, Hillen W. Exploring the sequence space for tetracycline-dependent transcriptional activators: novel mutations yield expanded range and sensitivity. Proc Natl Acad Sci USA. 2000;97(14):7963-8. https://doi.org/10.1073/pnas.130192197.

6. Sander JD, Joung JK. CRISPR-Cas systems for editing, regulating and targeting genomes. Nat Biotechnol. 2014;32(4):347-55. https://doi.org/10.1 038/nbt.2842.

7. Platt RJ, Chen S, Zhou Y, Yim MJ, Swiech L, Kempton HR, et al. CRISPR-Cas9 knockin mice for genome editing and cancer modeling. Cell. 2014;159(2): 440-55. https://doi.org/10.1016/j.cell.2014.09.014

8. Dubreuil V, Ramanantsoa N, Trochet D, Vaubourg V, Amiel J, Gallego J, et al. A human mutation in Phox2b causes lack of $\mathrm{CO} 2$ chemosensitivity, fatal central apnea, and specific loss of parafacial neurons. Proc Natl Acad Sci USA. 2008;105(3):1067-72. https://doi.org/10.1073/pnas.0709115105.

9. Zucker SN, Bancroft TA, Place DE, Des Soye B, Bagati A, Berezney R. A dominant negative CX43 mutant differentially affects tumorigenic and invasive properties in human metastatic melanoma cells. J Cell Physiol. 2013;228(4):853-9. https://doi.org/10.1002/jcp.24235.

10. LeMaster AM, Krimm RF, Davis BM, Noel T, Forbes ME, Johnson JE, et al. Overexpression of brain-derived neurotrophic factor enhances sensory innervation and selectively increases neuron number. J Neurosci. 1999; 19(14):5919-31. https://doi.org/10.1523/JNEUROSCl.19-14-05919.1999.

11. Collins AL, Levenson JM, Vilaythong AP, Richman R, Armstrong DL, Noebels $J$, et al. Mild overexpression of MeCP2 causes a progressive neurological disorder in mice. Hum Mol Genet. 2004;13(21):2679-89. https://doi.org/10.1 093/hmg/ddh282

12. Ellis T, Smyth I, Riley E, Bowles J, Adolphe C, Rothnagel JA, et al. Overexpression of Sonic Hedgehog suppresses embryonic hair follicle morphogenesis. Dev Biol. 2003;263(2):203-15. https://doi.org/10.1016/ S0012-1606(03)00394-4.

13. Ngo JT, Champion JA, Mahdavi A, Tanrikulu IC, Beatty KE, Connor RE, et al. Cell-selective metabolic labeling of proteins. Nat Chem Biol. 2009;5(10):7157. https://doi.org/10.1038/nchembio.200.

14. Doyle JP, Dougherty JD, Heiman M, Schmidt EF, Stevens TR, Ma G, et al. Application of a translational profiling approach for the comparative analysis of CNS cell types. Cell. 2008;135(4):749-62. https://doi.org/10.1016/j. cell.2008.10.029.

15. Marvin JS, Borghuis BG, Tian L, Cichon J, Harnett MT, Akerboom J, et al. An optimized fluorescent probe for visualizing glutamate neurotransmission. Nat Methods. 2013;10(2):162-70. https://doi.org/10.1038/nmeth.2333.

16. Akemann W, Mutoh H, Perron A, Park YK, Iwamoto Y, Knöpfel T. Imaging neural circuit dynamics with a voltage-sensitive fluorescent protein. J Neurophysiol. 2012;108(8):2323-37. https://doi.org/10.1152/jn.00452.2012.

17. Lin C-W, Sim S, Ainsworth A, Okada M, Kelsch W, Lois C. Genetically increased cell-intrinsic excitability enhances neuronal integration into adult brain circuits. Neuron. 2010;65(1):32-9. https://doi.org/10.1016/j.neuron.2 009.12.001.

18. Johns DC, Marx R, Mains RE, O'Rourke B, Marbán E. Inducible genetic suppression of neuronal excitability. J Neurosci. 1999;19(5):1691-7. https:// doi.org/10.1523/JNEUROSCI.19-05-01691.1999.

19. Ibañez-Tallon I, Wen H, Miwa JM, Xing J, Tekinay AB, Ono F, et al. Tethering naturally occurring peptide toxins for cell-autonomous modulation of ion channels and receptors in vivo. Neuron. 2004;43(3):305-11. https://doi.org/1 0.1016/j.neuron.2004.07.015.

20. Duan B, Cheng L, Bourane S, Britz O, Padilla C, Garcia-Campmany L, et al. Identification of spinal circuits transmitting and gating mechanical pain. Cell. 2014;159(6):1417-32. https://doi.org/10.1016/j.cell.2014.11.003.

21. Kim JC, Cook MN, Carey MR, Shen C, Regehr WG, Dymecki SM. Linking genetically defined neurons to behavior through a broadly applicable silencing allele. Neuron. 2009;63(3):305-15. https://doi.org/10.1016/j.neuron.2 009.07.010.

22. Conklin BR, Hsiao EC, Claeysen S, Dumuis A, Srinivasan S, Forsayeth JR, et al. Engineering GPCR signaling pathways with RASSLs. Nat Methods. 2008;5(8): 673-8. https://doi.org/10.1038/nmeth.1232. 
23. Beier KT, Samson MES, Matsuda T, Cepko CL. Conditional expression of the TVA receptor allows clonal analysis of descendents from Cre-expressing progenitor cells. Dev Biol. 2011;353(2):309-20. https://doi.org/10.1016/j. ydbio.2011.03.004

24. Magnus CJ, Lee PH, Atasoy D, Su HH, Looger LL, Sternson SM. Chemical and genetic engineering of selective ion channel-ligand interactions. Science. 2011;333(6047):1292-6. https://doi.org/10.1126/science.1206606.

25. Vardy E, Robinson JE, Li C, Olsen RHJ, DiBerto JF, Giguere PM, et al. A new DREADD facilitates the multiplexed chemogenetic interrogation of behavior. Neuron. 2015;86(4):936-46. https://doi.org/10.1016/j.neuron.2015.03.065.

26. Zhao R, Grunke SD, Keralapurath MM, Yetman MJ, Lam A, Lee T-C, et al. Impaired recall of positional memory following chemogenetic disruption of place field stability. Cell Rep. 2016;16(3):793-804. https://doi.org/10.1016/j. celrep.2016.06.032

27. Beier KT, Saunders A, Oldenburg IA, Miyamichi K, Akhtar N, Luo L, et al. Anterograde or retrograde transsynaptic labeling of CNS neurons with vesicular stomatitis virus vectors. Proc Natl Acad Sci USA. 2011;108(37) 15414-9. https://doi.org/10.1073/pnas.1110854108.

28. Wickersham IR, Finke S, Conzelmann K-K, Callaway EM. Retrograde neuronal tracing with a deletion-mutant rabies virus. Nat Methods. 2007;4(1):47-9. https://doi.org/10.1038/nmeth999.

29. Zeisel A, Muñoz-Manchado AB, Codeluppi S, Lönnerberg P, La Manno G, Juréus $A$, et al. Brain structure. Cell types in the mouse cortex and hippocampus revealed by single-cell RNA-seq. Science. 2015;347(6226): 1138-42. https://doi.org/10.1126/science.aaa1934.

30. Fuzik J, Zeisel A, Máté Z, Calvigioni D, Yanagawa Y, Szabó G, et al. Integration of electrophysiological recordings with single-cell RNA-seq data identifies neuronal subtypes. Nat Biotechnol. 2016;34(2):175-83. https://doi. org/10.1038/nbt.3443.

31. Cadwell CR, Palasantza A, Jiang X, Berens P, Deng Q, Yilmaz M, et al. Electrophysiological, transcriptomic and morphologic profiling of single neurons using Patch-seq. Nat Biotechnol. 2016;34(2):199-203. https://doi. org/10.1038/nbt.3445.

32. Awatramani R, Soriano P, Rodriguez C, Mai JJ, Dymecki SM. Cryptic boundaries in roof plate and choroid plexus identified by intersectional gene activation. Nat Genet. 2003;35(1):70-5. https://doi.org/10.1038/ng1228.

33. Han X, Zhang Z, He L, Zhu H, Li Y, Pu W, et al. A suite of new Dre recombinase drivers markedly expands the ability to perform intersectional genetic targeting. Cell Stem Cell. 2021;28(e7):1160-76. https://doi.org/10.101 6/j.stem.2021.01.007.

34. Hirsch M-R, d'Autréaux F, Dymecki SM, Brunet J-F, Goridis C. A Phox2b::FLPo transgenic mouse line suitable for intersectional genetics. Genesis. 2013; 51(7):506-14. https://doi.org/10.1002/dvg.22393.

35. Dymecki SM, Ray RS, Kim JC, Mapping cell fate and function using recombinase-based intersectional strategies. Guide to Techniques in Mouse Development, Part B: Mouse Molecular Genetics. 2nd ed: Elsevier; 2010. p. 183-213. https://doi.org/10.1016/S0076-6879(10)77011-7.

36. Robertson SD, Plummer NW, de Marchena J, Jensen P. Developmental origins of central norepinephrine neuron diversity. Nat Neurosci. 2013;16(8): 1016-23. https://doi.org/10.1038/nn.3458.

37. Brust RD, Corcoran AE, Richerson GB, Nattie E, Dymecki SM. Functional and developmental identification of a molecular subtype of brain serotonergic neuron specialized to regulate breathing dynamics. Cell Rep. 2014;9(6): 2152-65. https://doi.org/10.1016/j.celrep.2014.11.027.

38. Niederkofler V, Asher TE, Okaty BW, Rood BD, Narayan A, Hwa LS, et al. Identification of serotonergic neuronal modules that affect aggressive behavior. Cell Rep. 2016;17(8):1934-49. https://doi.org/10.1016/j.celrep.2016.10.063.

39. Ruffault P-L, D'Autréaux F, Hayes JA, Nomaksteinsky M, Autran S, Fujiyama T, et al. The retrotrapezoid nucleus neurons expressing Atoh 1 and Phox $2 \mathrm{~b}$ are essential for the respiratory response to $\mathrm{CO}_{2}$. Elife. 2015;4. https://doi.org/10. 7554/eLife.07051.

40. He M, Tucciarone J, Lee S, Nigro MJ, Kim Y, Levine JM, et al. Strategies and tools for combinatorial targeting of gabaergic neurons in mouse cerebral cortex. Neuron. 2016;91(6):1228-43. https://doi.org/10.1016/j. neuron.2016.08.021.

41. Madisen L, Garner AR, Shimaoka D, Chuong AS, Klapoetke NC, Li L, et al. Transgenic mice for intersectional targeting of neural sensors and effectors with high specificity and performance. Neuron. 2015;85(5):942-58. https:// doi.org/10.1016/j.neuron.2015.02.022.

42. Chen Y-W, Das M, Oyarzabal EA, Cheng Q, Plummer NW, Smith KG, et al. Genetic identification of a population of noradrenergic neurons implicated in attenuation of stress-related responses. Mol Psychiatry. 2019;24(5):710-25. https://doi.org/10.1038/s41380-018-0245-8.

43. Tervo DGR, Hwang B-Y, Viswanathan S, Gaj T, Lavzin M, Ritola KD, et al. A designer AAV variant permits efficient retrograde access to projection neurons. Neuron. 2016;92(2):372-82. https://doi.org/10.1016/j.neuron.2016. 09.021.

44. Zingg B, Chou X-L, Zhang Z-G, Mesik L, Liang F, Tao HW, et al. AAVmediated anterograde transsynaptic tagging: mapping corticocollicular input-defined neural pathways for defense behaviors. Neuron. 2017;93(1): 33-47. https://doi.org/10.1016/j.neuron.2016.11.045.

45. Kawano F, Okazaki R, Yazawa M, Sato M. A photoactivatable Cre-loxP recombination system for optogenetic genome engineering. Nat Chem Biol. 2016;12(12):1059-64. https://doi.org/10.1038/nchembio.2205.

46. Tang JCY, Rudolph S, Dhande OS, Abraira VE, Choi S, Lapan SW, et al. Cell type-specific manipulation with GFP-dependent Cre recombinase. Nat Neurosci. 2015;18(9):1334-41. https://doi.org/10.1038/nn.4081

47. DeNardo LA, Liu CD, Allen WE, Adams EL, Friedmann D, Fu L, et al. Temporal evolution of cortical ensembles promoting remote memory retrieval. Nat Neurosci. 2019;22(3):460-9. https://doi.org/10.1038/s41593-0180318-7.

48. Quadros RM, Miura H, Harms DW, Akatsuka H, Sato T, Aida T, et al. EasiCRISPR: a robust method for one-step generation of mice carrying conditional and insertion alleles using long SsDNA donors and CRISPR ribonucleoproteins. Genome Biol. 2017;18(1):92. https://doi.org/10.1186/s13 059-017-1220-4

49. Allen $W E$, Luo L. Intersectional illumination of neural circuit function. Neuron. 2015;85(5):889-92. https://doi.org/10.1016/j.neuron.2015.02.032.

50. Zambrowicz BP, Imamoto A, Fiering S, Herzenberg LA, Kerr WG, Soriano P. Disruption of overlapping transcripts in the ROSA beta geo 26 gene trap strain leads to widespread expression of beta-galactosidase in mouse embryos and hematopoietic cells. Proc Natl Acad Sci USA. 1997;94(8):378994. https://doi.org/10.1073/pnas.94.8.3789.

51. Soriano P. Generalized lacZ expression with the ROSA26 Cre reporter strain. Nat Genet. 1999;21(1):70-1. https://doi.org/10.1038/5007.

52. Ray RS, Corcoran AE, Brust RD, Kim JC, Richerson GB, Nattie E, et al. Impaired respiratory and body temperature control upon acute serotonergic neuron inhibition. Science. 2011;333(6042):637-42. https://doi.org/10.1126/ science.1205295.

53. Cong L, Ran FA, Cox D, Lin S, Barretto R, Habib N, et al. Multiplex genome engineering using CRISPR/Cas systems. Science. 2013;339(6121):819-23. https://doi.org/10.1126/science.1231143.

54. Sun JJ, Ray R. Generation of two noradrenergic-specific dopamine-betahydroxylase-FLPo knock-in mice using CRISPR/Cas9-mediated targeting in embryonic stem cells. PLOS ONE. 2016;11(7):e0159474. https://doi.org/10.13 71/journal.pone.0159474.

55. Thestrup T, Litzlbauer J, Bartholomäus I, Mues M, Russo L, Dana H, et al. Optimized ratiometric calcium sensors for functional in vivo imaging of neurons and T lymphocytes. Nat Methods. 2014;11(2):175-82. https://doi. org/10.1038/nmeth.2773.

56. Alexander GM, Rogan SC, Abbas Al, Armbruster BN, Pei Y, Allen JA, et al. Remote control of neuronal activity in transgenic mice expressing evolved G protein-coupled receptors. Neuron. 2009;63(1):27-39. https://doi.org/10.1 016/j.neuron.2009.06.014.

57. Guettier J-M. Gautam D, Scarselli M, Ruiz de Azua I, Li JH, Rosemond E, et al. A chemical-genetic approach to study $\mathrm{G}$ protein regulation of beta cell function in vivo. Proc Natl Acad Sci USA. 2009;106(45):19197-202. https:// doi.org/10.1073/pnas.0906593106.

58. Heiman M, Kulicke R, Fenster RJ, Greengard P, Heintz N. Cell type-specific mRNA purification by translating ribosome affinity purification (TRAP). Nat Protoc. 2014;9(6):1282-91. https://doi.org/10.1038/nprot.2014.085.

59. Li L, Tasic B, Micheva KD, Ivanov VM, Spletter ML, Smith SJ, et al. Visualizing the distribution of synapses from individual neurons in the mouse brain. PLoS ONE. 2010;5(7):e11503. https://doi.org/10.1371/journal.pone.0011503.

60. Root DH, Zhang S, Barker DJ, Miranda-Barrientos J, Liu B, Wang H-L, et al. Selective brain distribution and distinctive synaptic architecture of dual glutamatergic-GABAergic neurons. Cell Rep. 2018;23(12):3465-79. https://doi. org/10.1016/j.celrep.2018.05.063.

61. Shabel SJ, Proulx CD, Piriz J, Malinow R. Mood regulation. GABA/glutamate co-release controls habenula output and is modified by antidepressant treatment. Science. 2014;345(6203):1494-8. https://doi.org/10.1126/ science.1250469. 
62. Hnasko TS, Perez FA, Scouras AD, Stoll EA, Gale SD, Luquet S, et al. Cre recombinase-mediated restoration of nigrostriatal dopamine in dopaminedeficient mice reverses hypophagia and bradykinesia. Proc Natl Acad Sci USA. 2006;103(23):8858-63. https://doi.org/10.1073/pnas.0603081103.

63. Soudais C, Laplace-Builhe C, Kissa K, Kremer EJ. Preferential transduction of neurons by canine adenovirus vectors and their efficient retrograde transport in vivo. FASEB J. 2001;15(12):2283-5. https://doi.org/10.1096/fj.01 0321fje.

64. Plummer NW, Chandler DJ, Powell JM, Scappini EL, Waterhouse BD, Jensen P. An Intersectional viral-genetic method for fluorescent tracing of axon collaterals reveals details of noradrenergic locus coeruleus structure. Eneuro. 2020;7(3):ENEURO.0010-20.2020. https://doi.org/10.1523/ENEURO.0010-20.2020.

65. Rodríguez Cl, Buchholz F, Galloway J, Sequerra R, Kasper J, Ayala R, et al. High-efficiency deleter mice show that FLPe is an alternative to Cre-loxP. Nat Genet. 2000;25(2):139-40. https://doi.org/10.1038/75973.

66. Bang SJ, Jensen P, Dymecki SM, Commons KG. Projections and interconnections of genetically defined serotonin neurons in mice. Eur J Neurosci. 2012;35(1):85-96. https://doi.org/10.1111/j.1460-9568.2011.07936.x.

67. Egbert JR, Fahey PG, Reimer J, Owen CM, Evsikov AV, Nikolaev VO, et al. Follicle-stimulating hormone and luteinizing hormone increase $\mathrm{Ca} 2+$ in the granulosa cells of mouse ovarian folliclest. Biol Reprod. 2019;101(2):433-44. https://doi.org/10.1093/biolre/ioz085.

68. Wang B, Li K, Wang A, Reiser M, Saunders T, Lockey RF, et al. Highly efficient CRISPR/HDR-mediated knock-in for mouse embryonic stem cells and zygotes. BioTechniques. 2015;59(204) 206:201-2. https://doi.org/10.2144/ 000114339.

69. Chu VT, Weber T, Graf R, Sommermann T, Petsch K, Sack U, et al. Efficient generation of Rosa26 knock-in mice using CRISPR/Cas9 in C57BL/6 zygotes. BMC Biotechnol. 2016;16(1):4. https://doi.org/10.1186/s12896-016-0234-4

70. Yoshimi K, Kunihiro Y, Kaneko T, Nagahora H, Voigt B, Mashimo T. ssODNmediated knock-in with CRISPR-Cas for large genomic regions in zygotes. Nat Commun. 2016;7:10431. https://doi.org/10.1038/ncomms10431.

71. Jensen P, Farago AF, Awatramani RB, Scott MM, Deneris ES, Dymecki SM. Redefining the serotonergic system by genetic lineage. Nat Neurosci. 2008; 11(4):417-9. https://doi.org/10.1038/nn2050.

72. Bochkov YA, Palmenberg AC. Translational efficiency of EMCV IRES in bicistronic vectors is dependent upon IRES sequence and gene location. BioTechniques. 2006;41(286) 288 passim:283-4. https://doi.org/10.2144/ 000112243.

73. Viemari J-C, Roux J-C, Tryba AK, Saywell V, Burnet H, Peña F, et al. Mecp2 deficiency disrupts norepinephrine and respiratory systems in mice. J Neurosci. 2005;25(50):11521-30. https://doi.org/10.1523/JNEUROSCI.437305.2005 .

74. Viemari J-C, Ramirez J-M. Norepinephrine differentially modulates different types of respiratory pacemaker and nonpacemaker neurons. J Neurophysiol. 2006;95(4):2070-82. https://doi.org/10.1152/jn.01308.2005

75. Li A, Emond L, Nattie E. Brainstem catecholaminergic neurons modulate both respiratory and cardiovascular function. Adv Exp Med Biol. 2008;605: 371-6. https://doi.org/10.1007/978-0-387-73693-8_65.

76. Biancardi V, Bícego KC, Almeida MC, Gargaglioni LH. Locus coeruleus noradrenergic neurons and CO2 drive to breathing. Pflugers Arch. 2008; 455(6):1119-28. https://doi.org/10.1007/s00424-007-0338-8.

77. Viemari J-C. Noradrenergic modulation of the respiratory neural network Respir Physiol Neurobiol. 2008;164(1-2):123-30. https://doi.org/10.1016/j. resp.2008.06.016.

78. Gargaglioni LH, Hartzler LK, Putnam RW. The locus coeruleus and central chemosensitivity. Respir Physiol Neurobiol. 2010;173(3):264-73. https://doi. org/10.1016/j.resp.2010.04.024.

79. Kuo F-S, Falquetto B, Chen D, Oliveira LM, Takakura AC, Mulkey DK. In vitro characterization of noradrenergic modulation of chemosensitive neurons in the retrotrapezoid nucleus. J Neurophysiol. 2016;116(3):1024-35. https://doi. org/10.1152/jn.00022.2016

80. Engelbrecht AH, Russell V, Carstens ME, De Villiers AS, Searson A, Jaffer A, et al. Evidence that noradrenergic neurons in the $A 1$ and $A 2$ nuclei are lesioned by low doses of 6-OHDA injected into the locus coeruleus. J Neurosci Methods. 1994;52(1):57-60. https://doi.org/10.1016/0165-0270(94 )90056-6.

81. Massey CA, Iceman $K E$, Johansen $S L$, Wu Y, Harris MB, Richerson GB. Isoflurane abolishes spontaneous firing of serotonin neurons and masks their pH/CO 2 chemosensitivity. J Neurophysiol. 2015;113(7):2879-88. https:// doi.org/10.1152/jn.01073.2014.
82. Cooper KE, Jones DL, Pittman QJ, Veale WL. The effect of noradrenaline, injected into the hypothalamus, on thermoregulation in the cat. J Physiol (Lond). 1976;261:211-22. https://doi.org/10.1113/jphysiol.1976.sp011554.

83. Handley SL, Spencer PS. thermoregulatory effects of intraventricular injection of noradrenaline in the mouse and the influence of ambient temperature. J Physiol (Lond). 1972;223(3):619-31. https://doi.org/10.1113/ jphysiol.1972.sp009865.

84. Guyenet PG, Bayliss DA. Neural control of breathing and $\mathrm{CO} 2$ homeostasis. Neuron. 2015;87(5):946-61. https://doi.org/10.1016/j.neuron.2015.08.001.

85. Ray RS, Corcoran AE, Brust RD, Soriano LP, Nattie EE, Dymecki SM. Egr2neurons control the adult respiratory response to hypercapnia. Brain Res. 2013;1511:115-25. https://doi.org/10.1016/j.brainres.2012.12.017.

86. Hennessy ML, Corcoran AE, Brust RD, Chang Y, Nattie EE, Dymecki SM. Activity of tachykinin1-expressing Pet1 Raphe neurons modulates the respiratory chemoreflex. J Neurosci. 2017;37(7):1807-19. https://doi.org/10.1 523/JNEUROSCI.2316-16.2016.

87. Martinez VK, Saldana-Morales F, Sun JJ, Zhu PJ, Costa-Mattioli M, Ray RS. Offtarget effects of clozapine-N-oxide on the chemosensory reflex are masked by high stress levels. Front Physiol. 2019;10:521. https://doi.org/10.3389/ fphys.2019.00521.

88. Ting JT, Daigle TL, Chen Q, Feng G. Acute brain slice methods for adult and aging animals: application of targeted patch clamp analysis and optogenetics. Patch

89. Jiang X, Shen S, Cadwell CR, Berens P, Sinz F, Ecker AS, et al. Principles of connectivity among morphologically defined cell types in adult neocortex. Science. 2015;350:aac9462. https://doi.org/10.1126/science.aac9462.

90. Scala F, Kobak D, Shan S, Bernaerts Y, Laturnus S, Cadwell CR, et al. Layer 4 of mouse neocortex differs in cell types and circuit organization between sensory areas. Nat Commun. 2019;10(1):4174. https://doi.org/10.1038/s414 67-019-12058-z.

91. Scala F, Kobak D, Bernabucci M, Bernaerts Y, Cadwell CR, Castro JR, et al. Phenotypic variation of transcriptomic cell types in mouse motor cortex. Nature. 2020:598(7879):144-50. https://doi.org/10.1038/s41586-020-2907-3.

92. Schielzeth $H$, Dingemanse NJ, Nakagawa S, Westneat DF, Allegue $H$, Teplitsky C, et al. Robustness of linear mixed-effects models to violations of distributional assumptions. Methods Ecol Evol. 2020;11(9):1141-52. https:// doi.org/10.1111/2041-210X.13434

93. Shuhaibar LC, Egbert JR, Norris RP, Lampe PD, Nikolaev VO, Thunemann M, et al. Intercellular signaling via cyclic GMP diffusion through gap junctions restarts meiosis in mouse ovarian follicles. Proc Natl Acad Sci USA. 2015; 112(17):5527-32. https://doi.org/10.1073/pnas.1423598112.

\section{Publisher's Note}

Springer Nature remains neutral with regard to jurisdictional claims in published maps and institutional affiliations.

Ready to submit your research? Choose BMC and benefit from

- fast, convenient online submission

- thorough peer review by experienced researchers in your field

- rapid publication on acceptance

- support for research data, including large and complex data types

- gold Open Access which fosters wider collaboration and increased citations

- maximum visibility for your research: over $100 \mathrm{M}$ website views per year

At BMC, research is always in progress.

Learn more biomedcentral.com/submissions 